\title{
Evolvable, sustainable, low power optical network architectures
}

\author{
Prof. David Payne \\ CTVR, Trinity College Dublin
}




\section{Acknowledgments}

\section{Dr. Marco Ruffini}

CTVR, Trinity College Dublin

Prof. Linda Doyle

Director CTVR, Trinity College Dublin

\section{and}

Prof. Nick Doran and Dr. Farsheed Farjady

Swansea University, Wales

This material is based upon works supported by the Science

Foundation Ireland under Grant No. 10/CE/I1853 


\section{ICT and telecommunications}

\section{networks can be part of the}

\section{solution for addressing}

climate change, not part of

the problem! 


\section{Evolvable \& sustainable networks:}

- Remains economically viable

- as demand and services evolve

- and supports a range of business and ownership models

- Low power consumption

- "Green" network solutions

- Can scale to meet service growth requirements

- particularly those enabled by FTTP

- Access bandwidth scales indefinitely up to limits of fibre technology.

- Can adopt new technologies

- while co-existing with previous generations

- re-use installed physical infrastructure

- Efficiently use network resources

- e.g. spectrum, bandwidth, infrastructure (cables \& fibre), equipment and components, man-power, processing power, space, storage etc.

- Major reduction in electronic equipment per unit of user bandwidth.

- Reduced number of nodes, interface ports, OEO conversions, and line cards.

- Cost per unit bandwidth needs to fall almost inline with bandwidth growth! 


\section{Today's Electronics Centric Architecture}

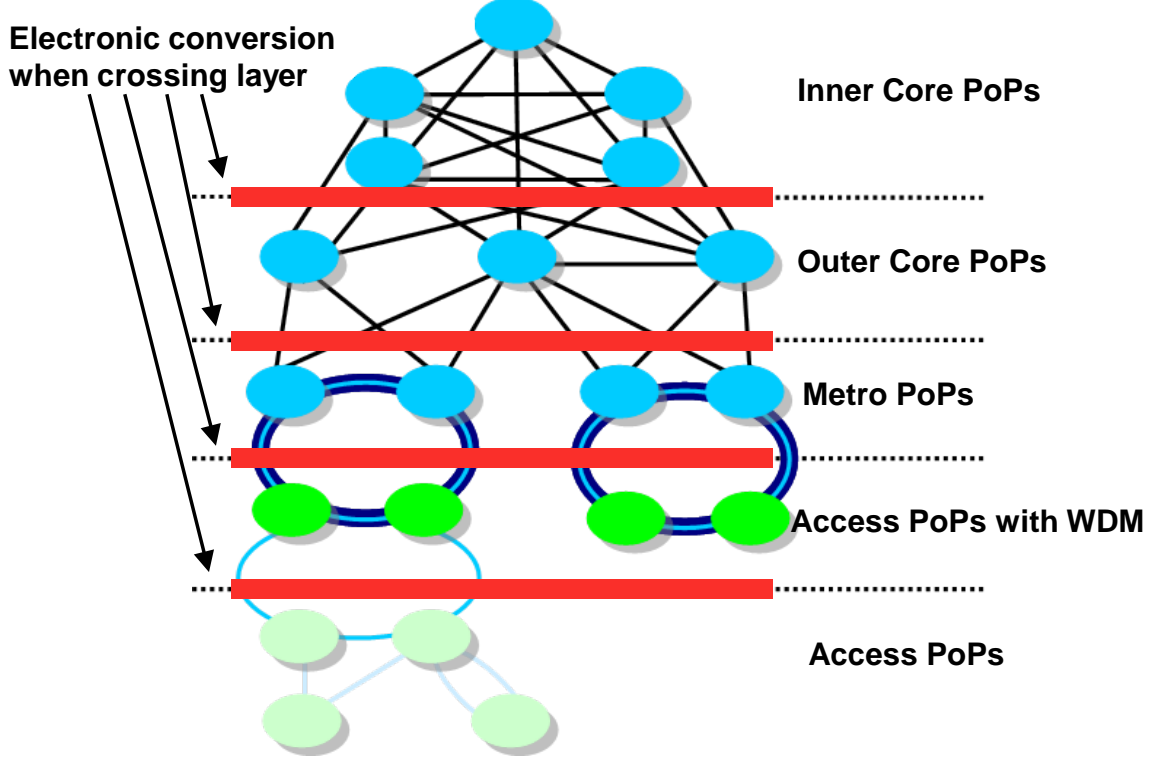

\section{Future Optical Network Architecture}
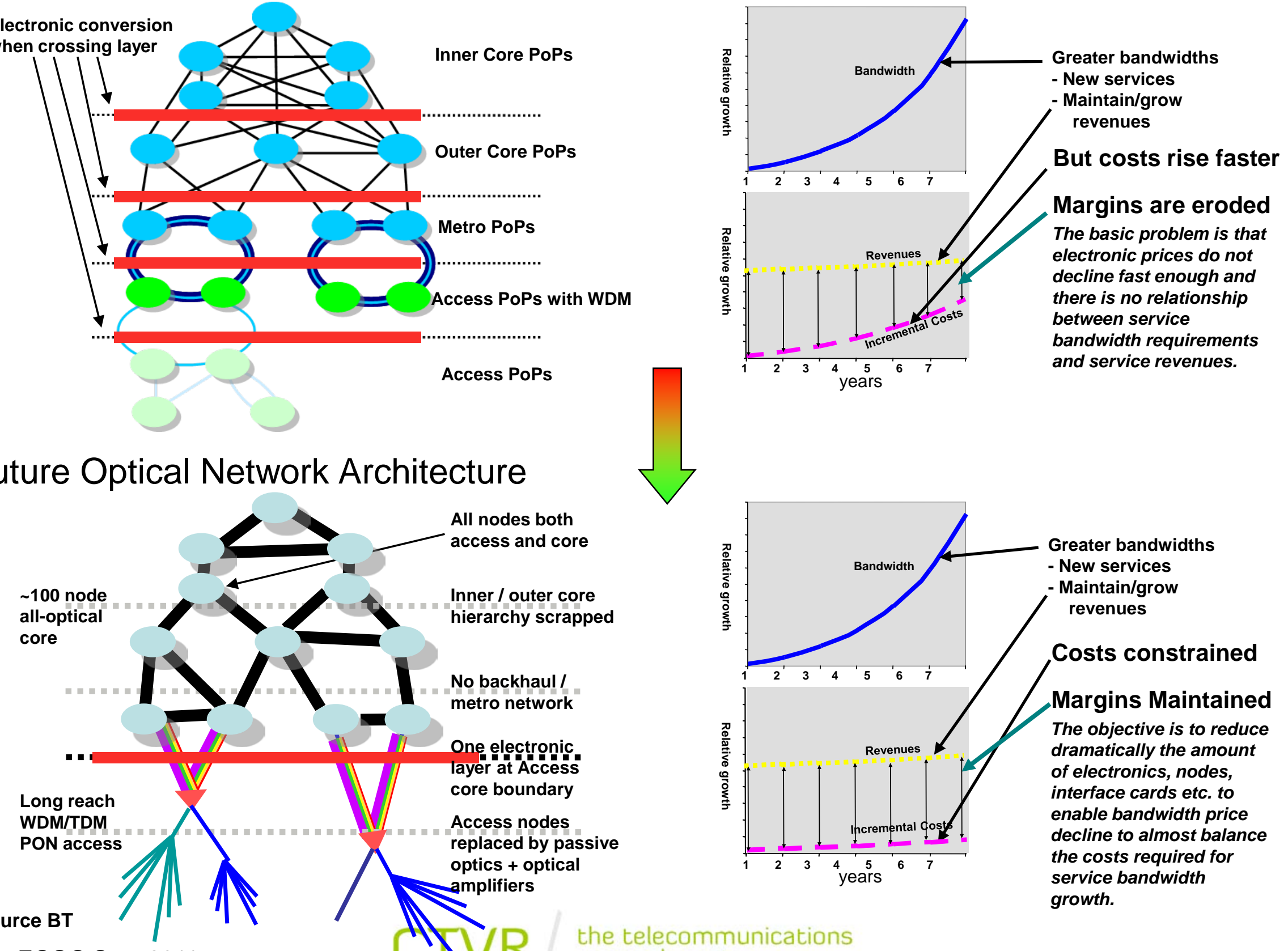

ECOC Sept 2011 


\section{Future network architecture}

- Fibre to the premises access networks

- Necessary for future service and bandwidth requirements.

- Elimination of majority of central offices/local exchanges.

- Reduces node count, port count and line card count

- Bypass Metro networks

- Long reach access direct to core

- Optical core network with optical circuit switching

- Reduces core network OEO conversions and minimises core packet router size. 


\section{Cost effective and Energy efficient architecture}

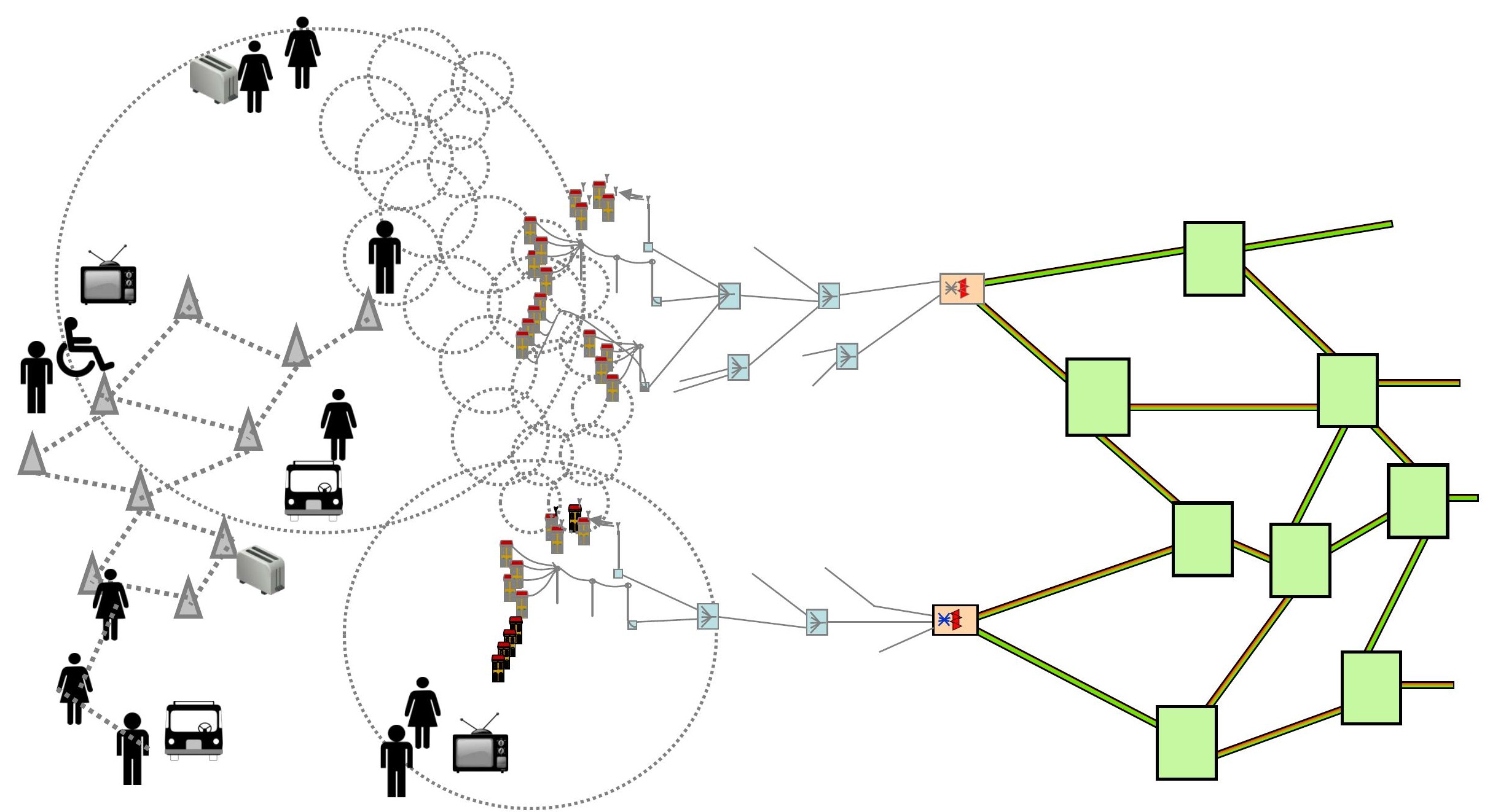

self-architecting wireless + FTTH via LR-PON + flat core 
Access nodes (Local Exchange) in electronic centric network architecture

Small Local Exchange with Copper MSAN only (no fibre customers)

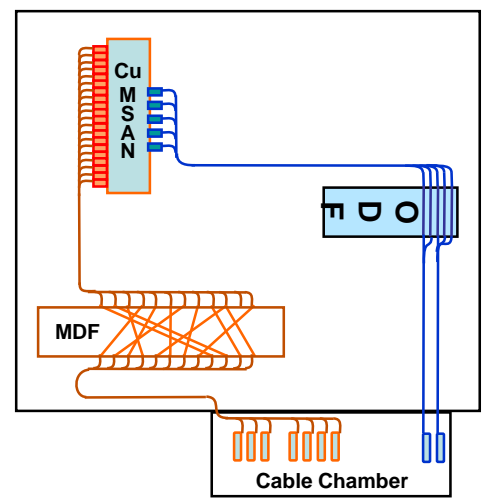

$\sqrt{1}$
Medium Local Exchange with Copper MSAN \& Fibre MSAN

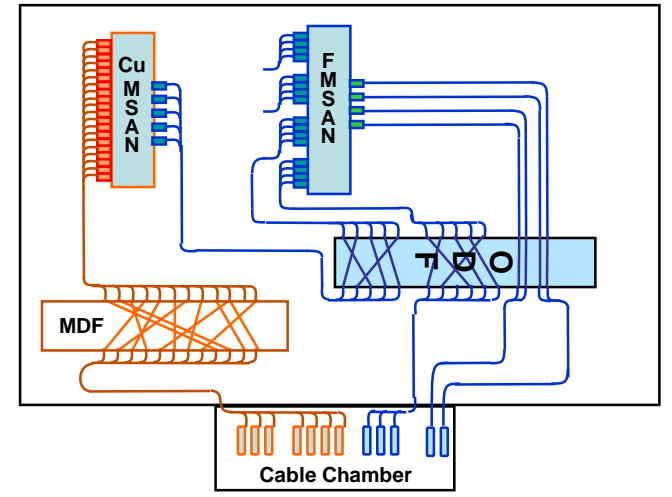

П
Large Local Exchange with Copper MSAN, Fibre MSAN \& WDM MSAN

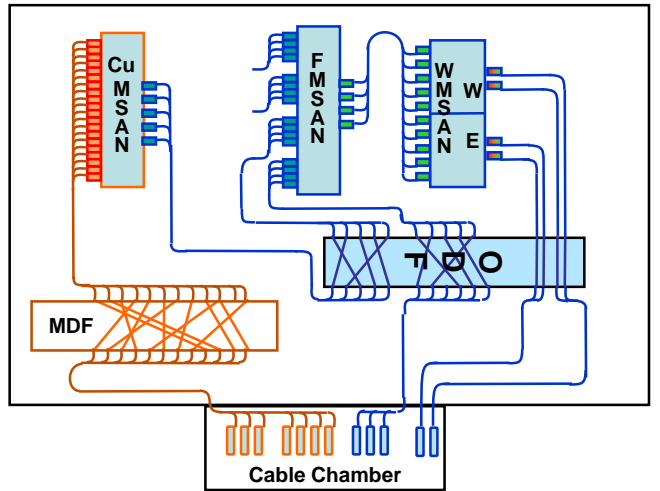

$\sqrt{1}$

Access nodes in LR-PON optical network architecture
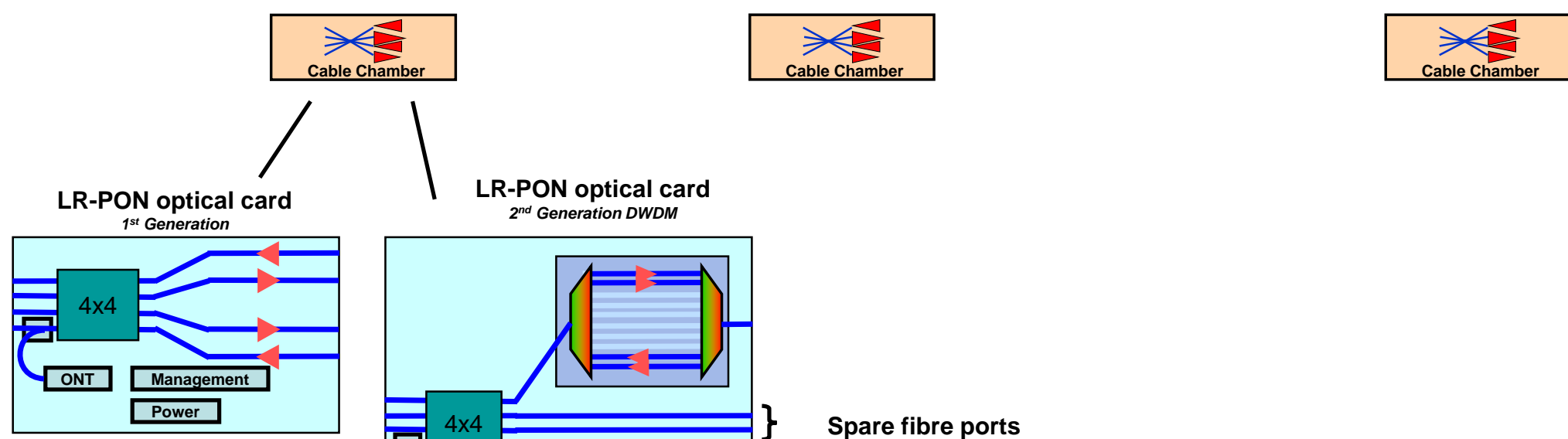

Cable Chamber

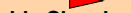

Cable Chamber 


\section{Optical Core Node Structure}

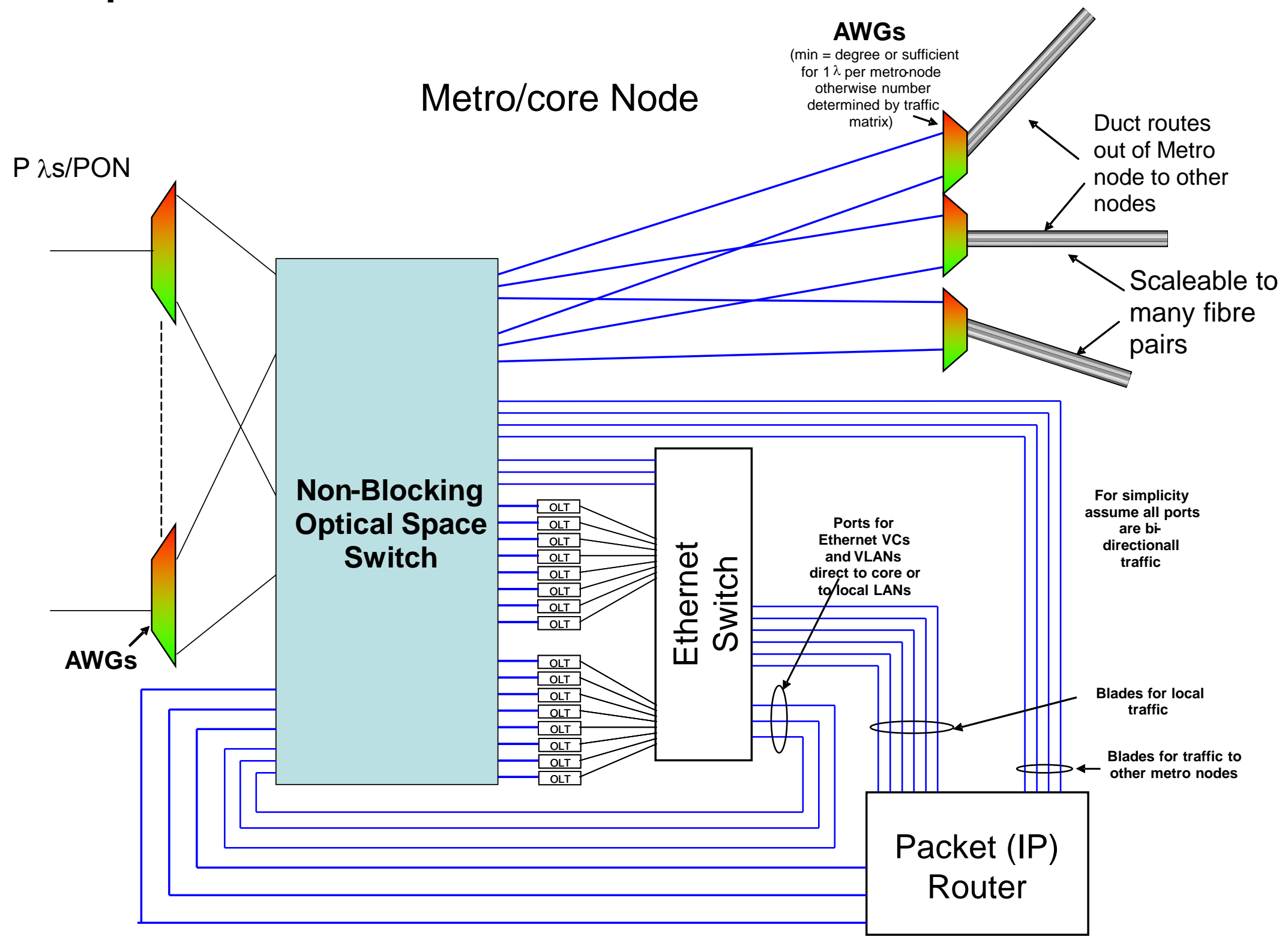




\section{Simplification of country network (Ireland example)}
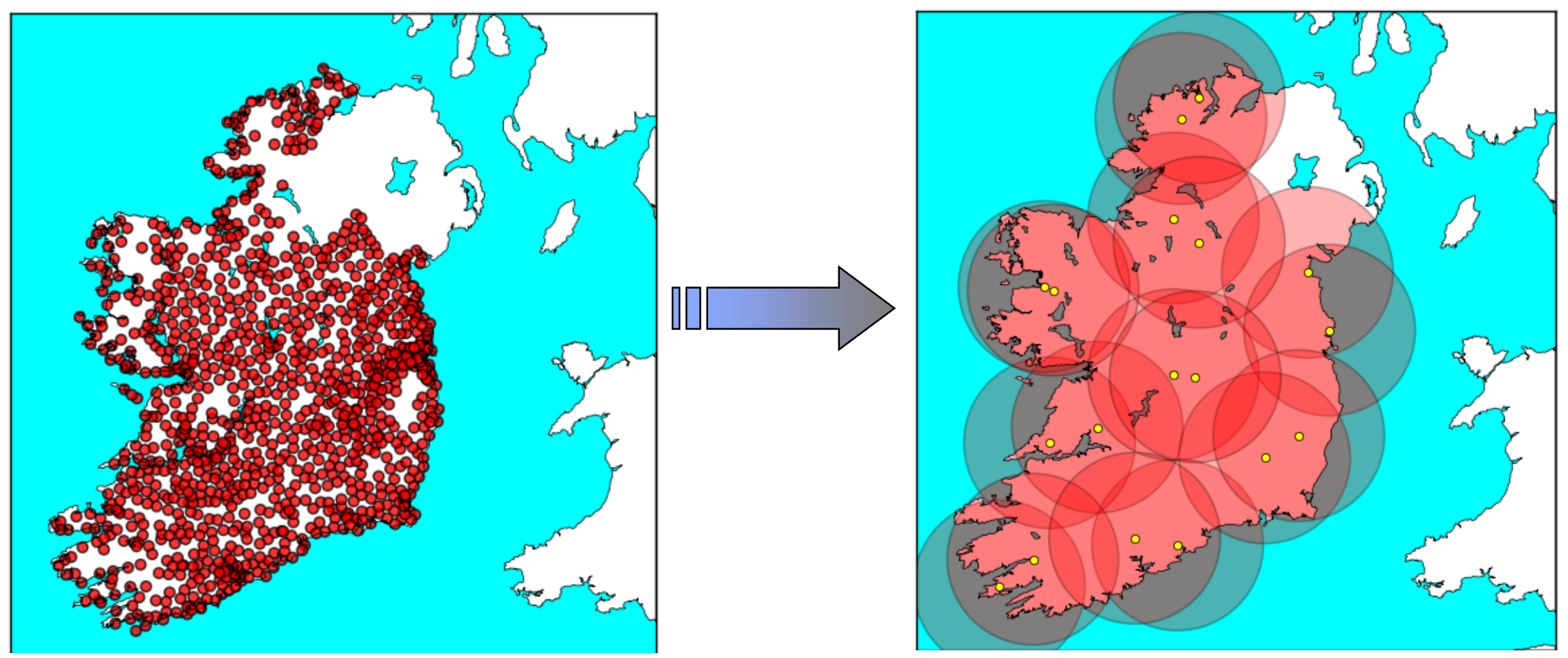

Ireland with all 1100 exchange buildings

Ireland with 18 nodes 


\section{Simplification of country network (UK example)}
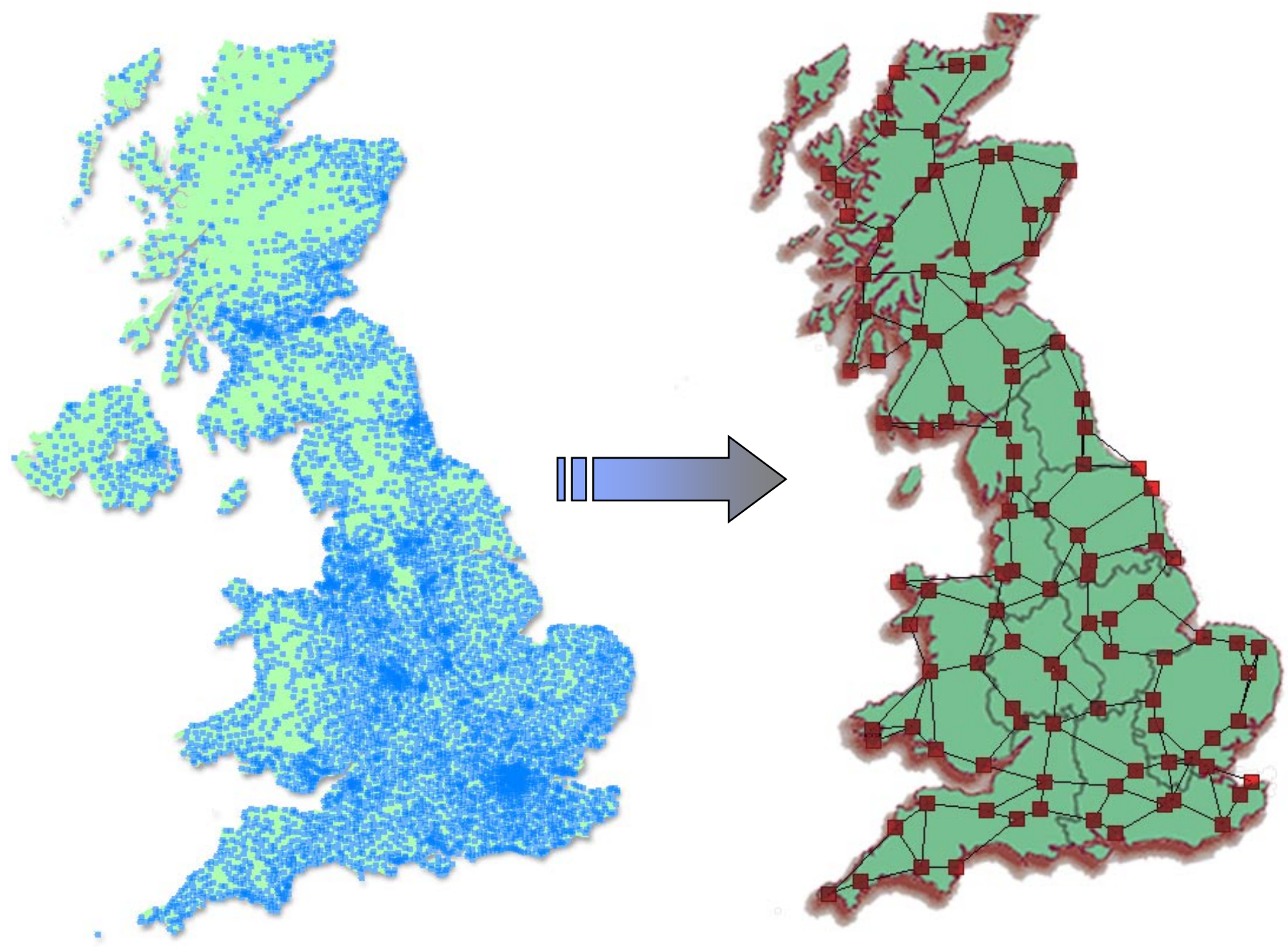

UK With All Exchanges

Source BT 


\section{Economic comparisons}

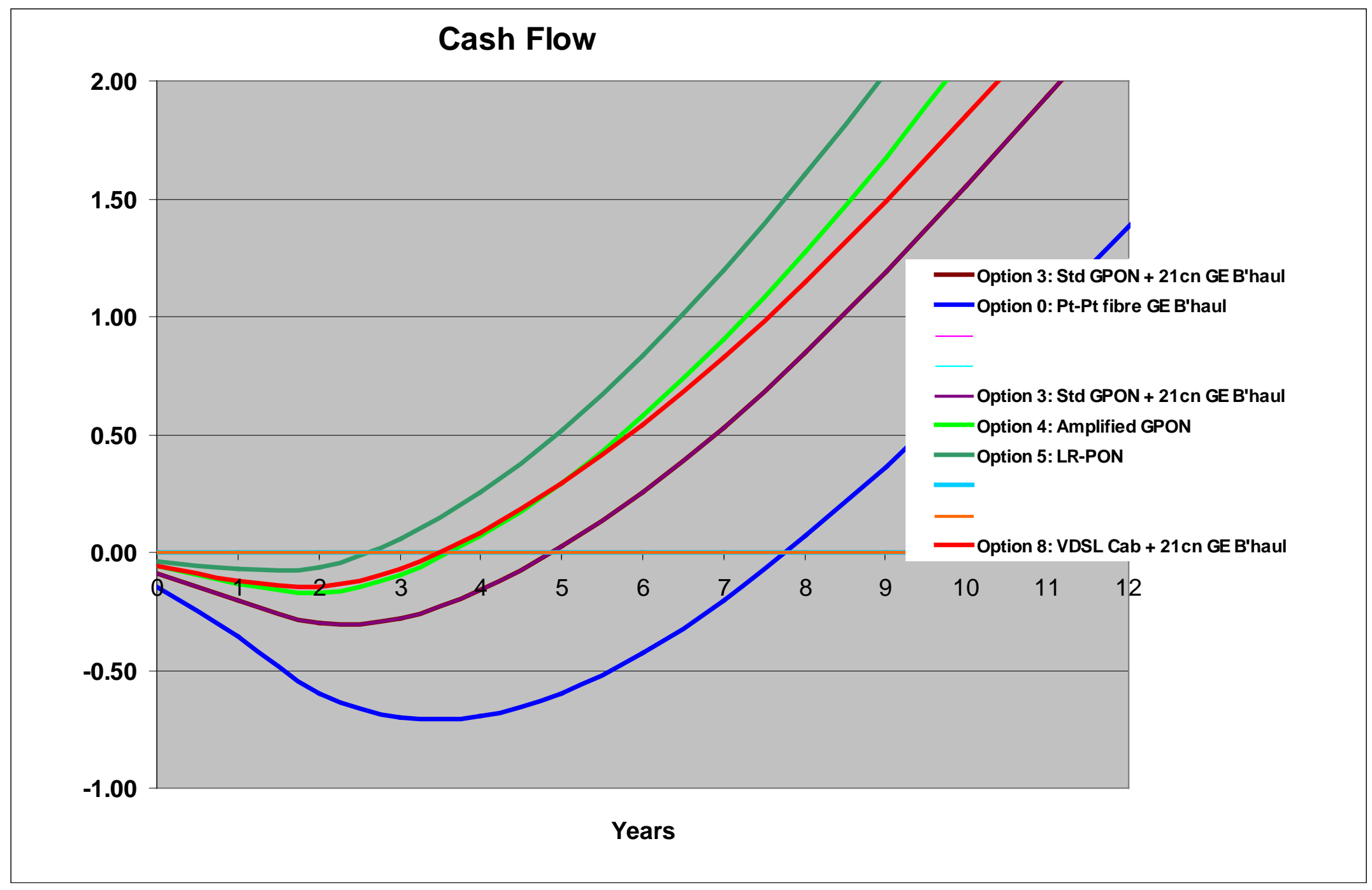

Source BT

ECOC Sept 2011 


\section{Operational \& Environmental Benefits "Green Network"}

Based on Ipswich Exchange serving 15,000 customers

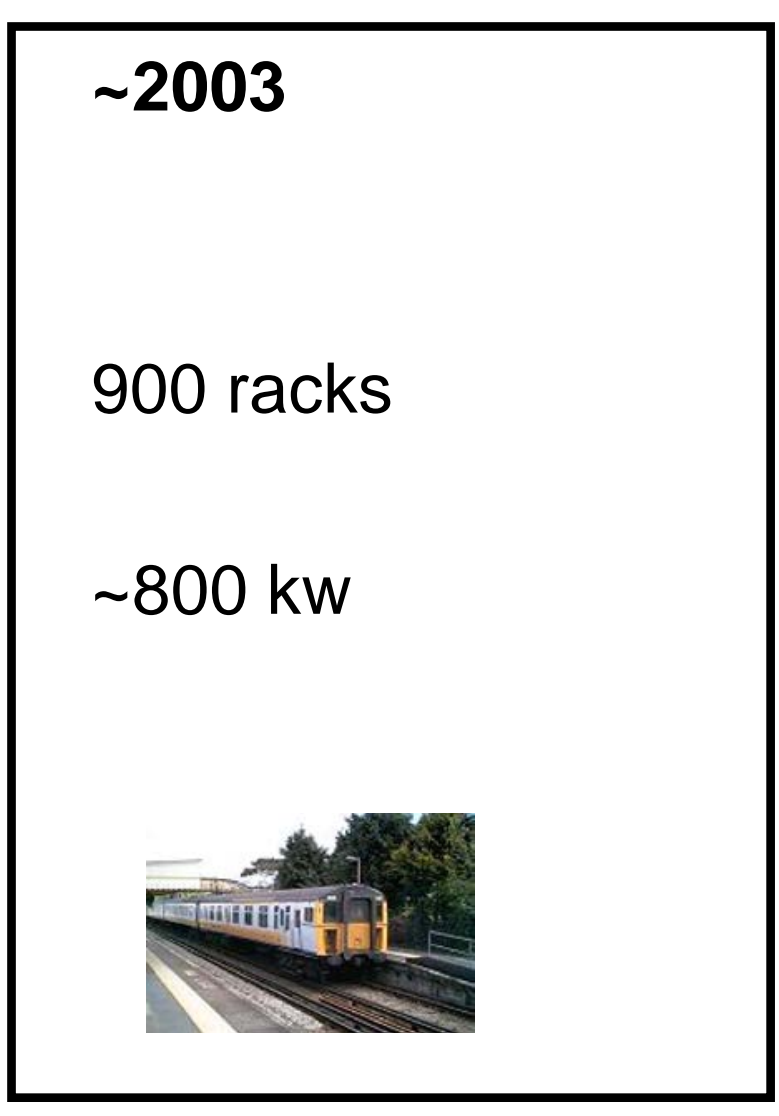

Source BT

ECOC Sept 2011

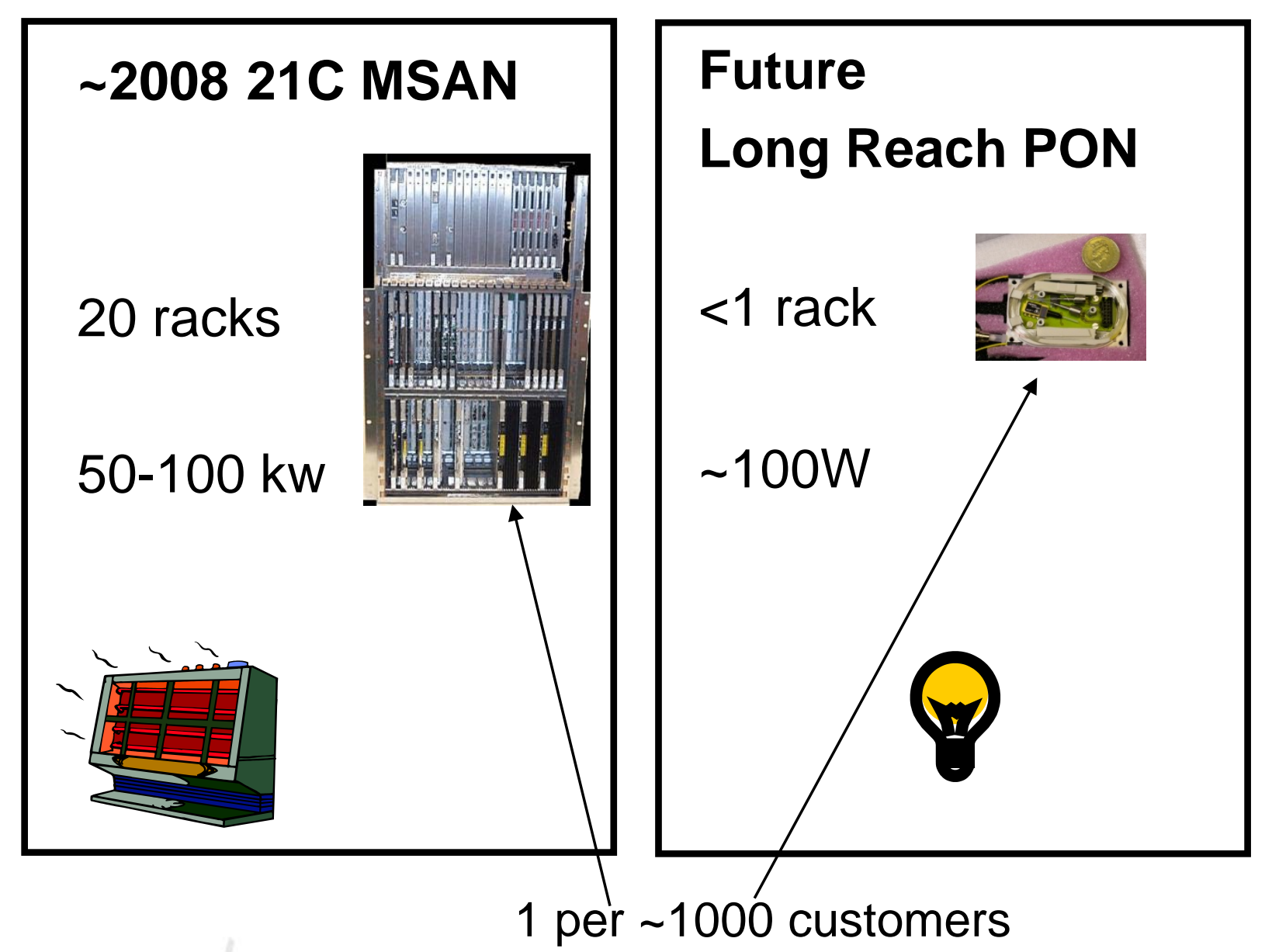




\section{User power BAU v LR-PON + flat core}

Power per user: BAU v LR-PON + flat core

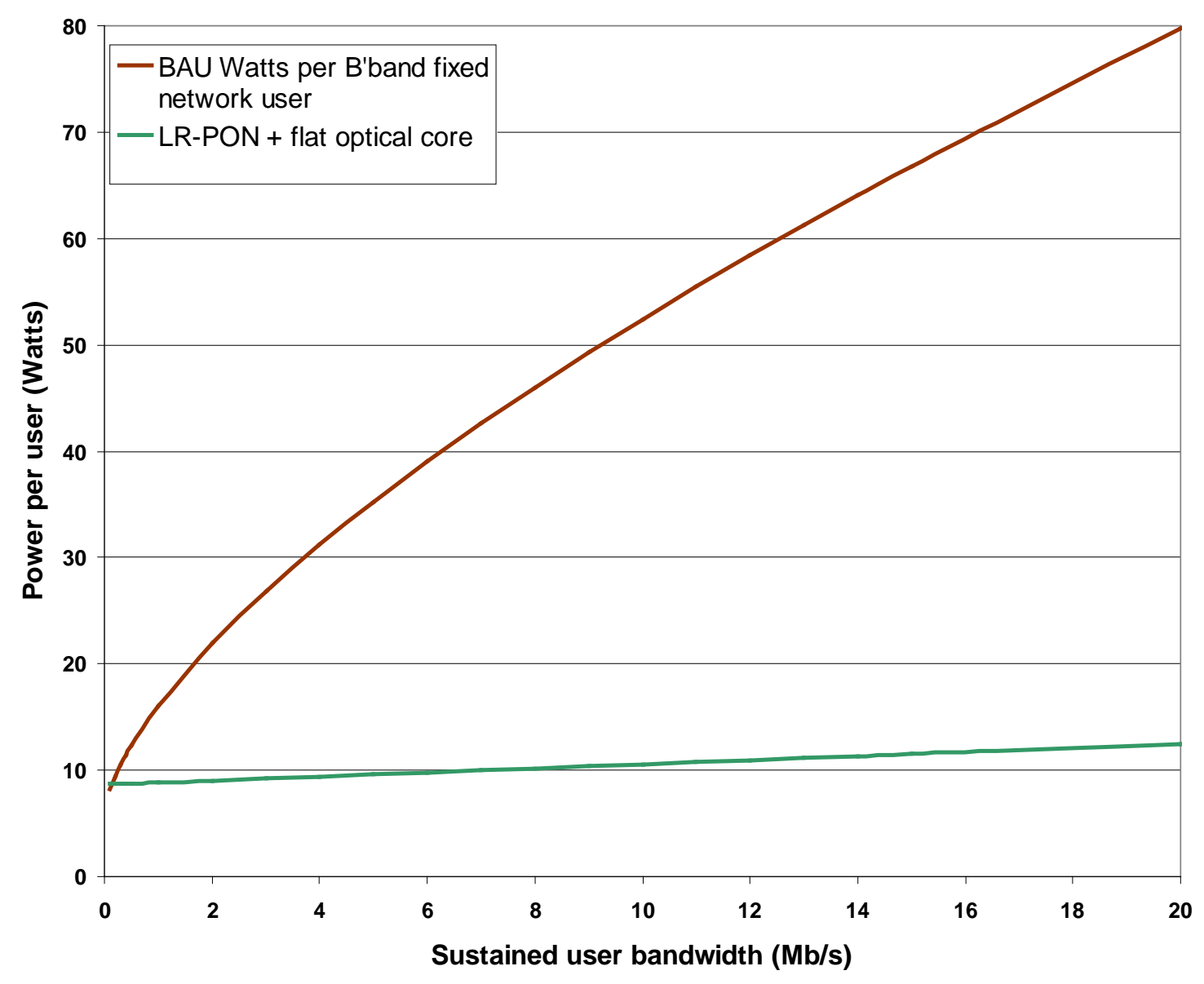

Comparison of relative power consumption against user sustained bandwidth. BAU case versus LR-PON plus flat optical core.

\section{LR-PON case power} consumption is dominated by access power (ONU) consumption.

BAU quickly becomes dominated by core network power consumption as user bandwidth rise. 


\section{Environmental considerations}

\section{Synopsis of World Energy Problem:}

- Solar energy input on Earth's surface $=1.07 \times 10^{9} \mathrm{TWhrs} / \mathrm{yr}$

- 2010 world primary energy usage $=1.48 \times 10^{5} \mathrm{TWhrs} / \mathrm{yr}$

- Ratio human to solar energy input $=1 / 7700$.

- Gives rise to $0.01^{\circ} \mathrm{C}$ average temperature rise if NO green house gases were produced.

- Problem is not energy consumption it is green house gas emissions.

- Can ICT help reduce carbon emissions and be at least carbon neutral of even carbon negative?

- Smart 2020 report suggests the environmental benefit from ICT could be five times its environmental cost by 2020

- Can the architecture for cost reduction also be used for environmental sustainability? 


\section{World energy use}

World Primary Energy and Projected Growth

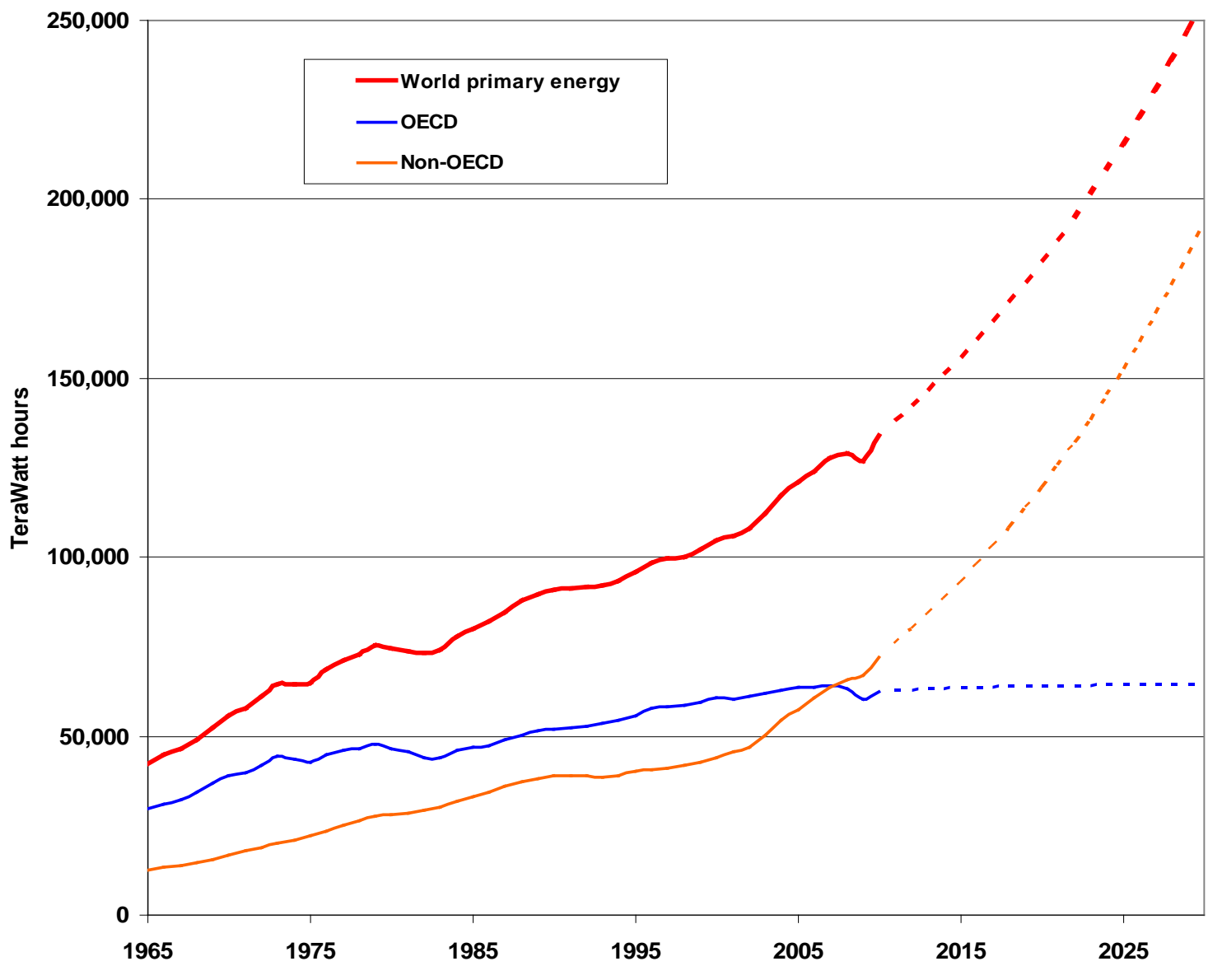

Most of the growth in primary energy use is from the developing non OECD countries particularly the BRIC countries Brazil, Russia, China and India.

But per capita use still lags the OECD.

These projections are trend lines but assume renewables grow at $11 \%$ per annum to 2030. They are therefore less pessimistic than the Smart 2020 BAU case.

Sources:

REN21. 2011. Renewables 2011 Global

Status Report).

BP statistical review.

IEA 


\section{World $\mathrm{CO}_{2}$ emissions}

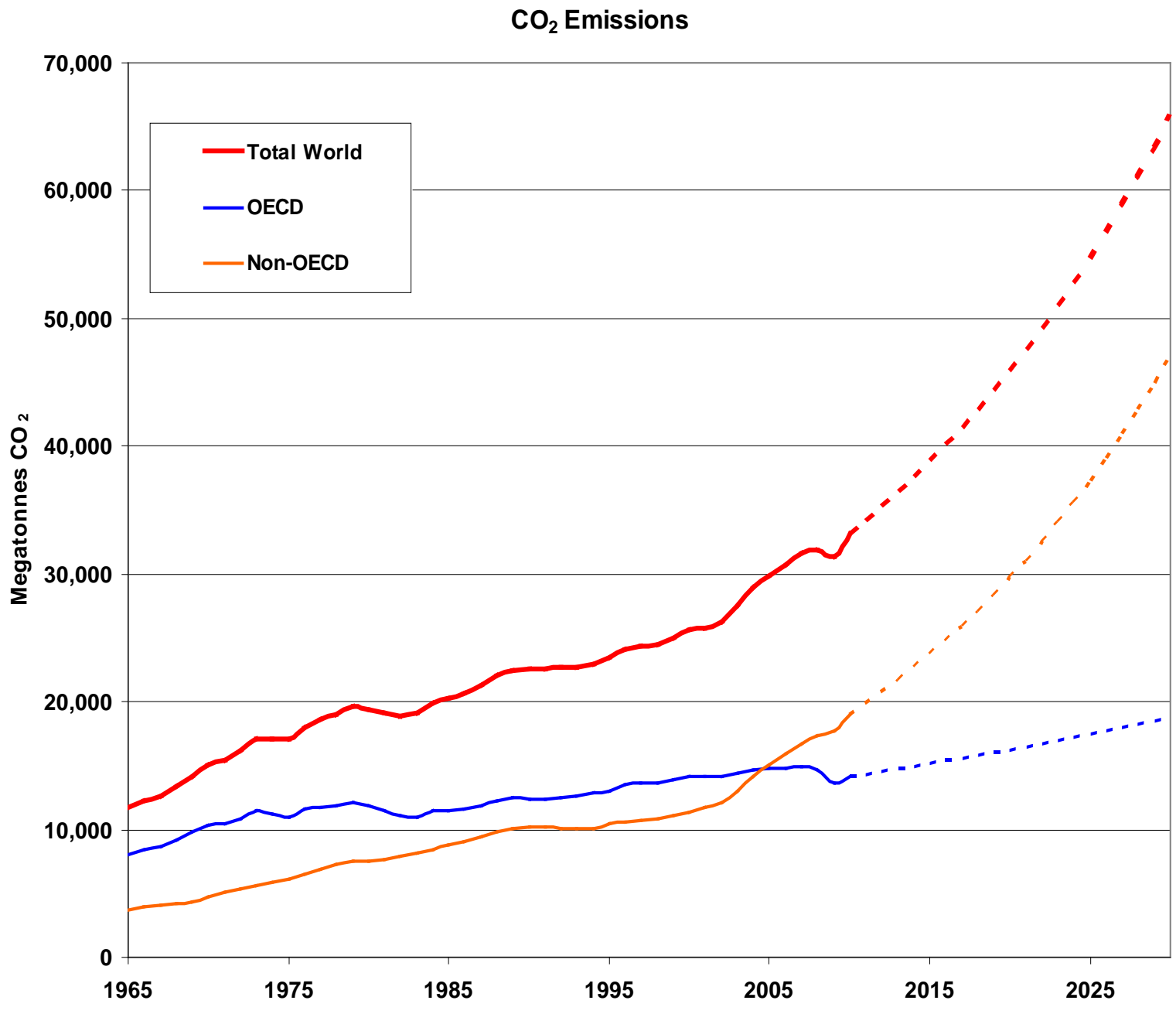

Growth in $\mathrm{CO}_{2}$ largely tracks growth in primary energy because renewables even at $11 \%$ growth do not have enough impact. 


\section{World energy use by fuel type}

World Primary energy by fuel type (TWHrs)

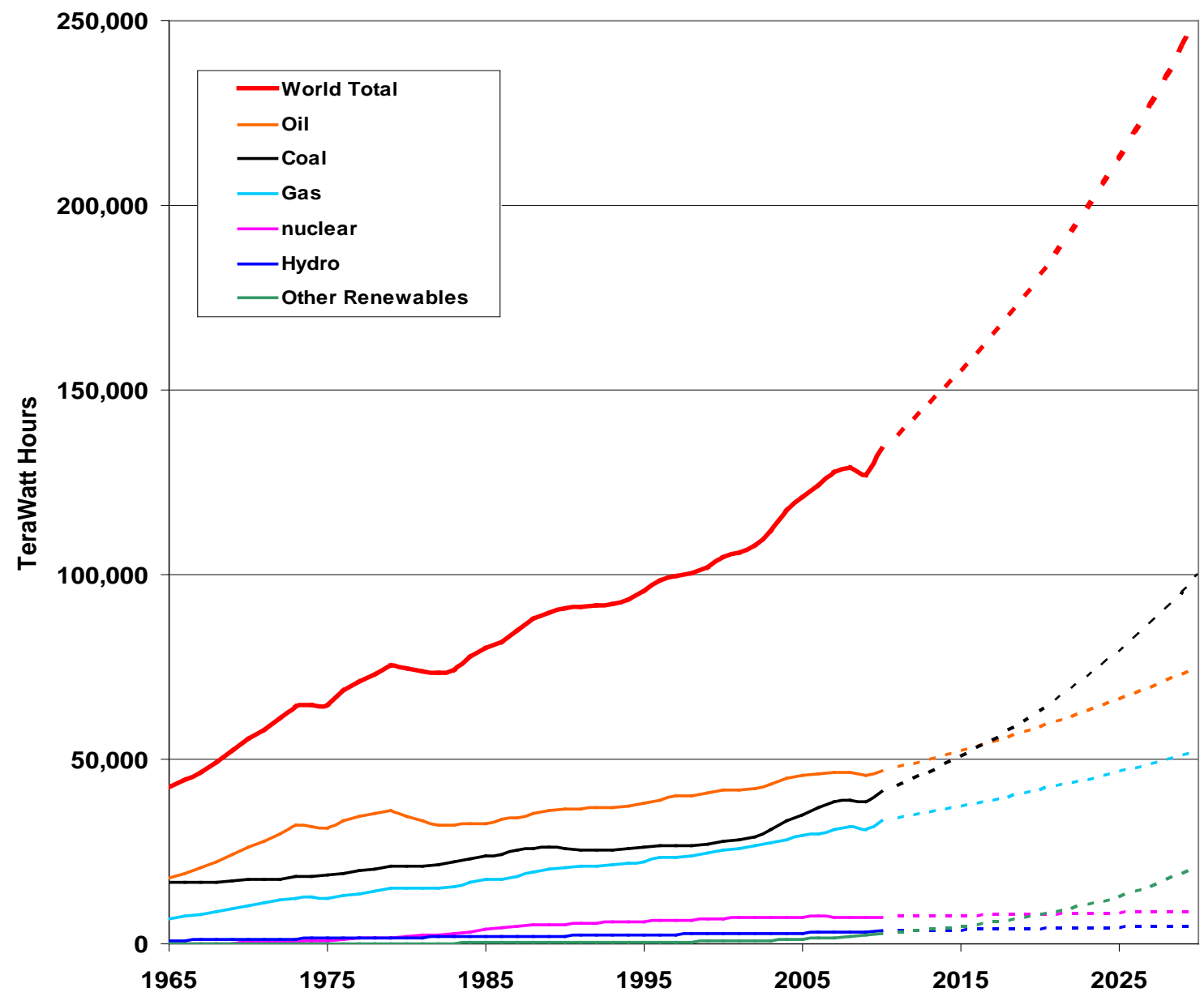

The dominant fuels are the fossil fuels Coal, Oil and Gas

Note that Coal exceeds Oil after $\sim 2015$ due to the growth of coal usage in nonOECD countries particularly China.

In this scenario Renewables grow slower than Coal using the $11 \%$ renewable growth rate. 


\section{World $\mathrm{CO}_{2}$ emissions by fuel type}

World $\mathrm{CO}_{2}$ Emissions by fuel type

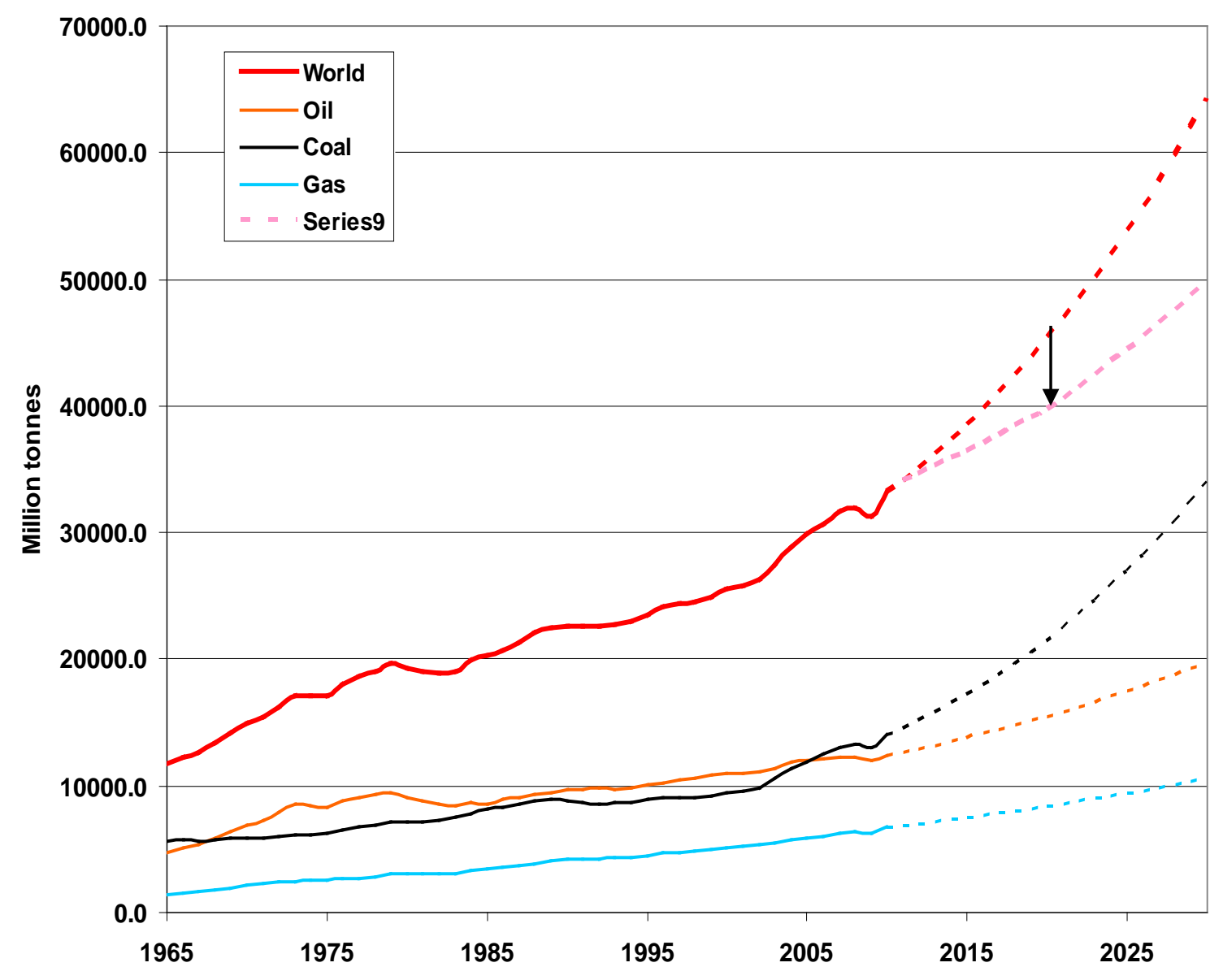

Growth in $\mathrm{CO}_{2}$ largely tracks growth in primary energy because renewables even at $11 \%$ growth do not have enough impact.

The arrow shows the benefit produced by ICT this result is pro-rated from the Smart2020 study for the year 2020. 


\section{Electricity generation}

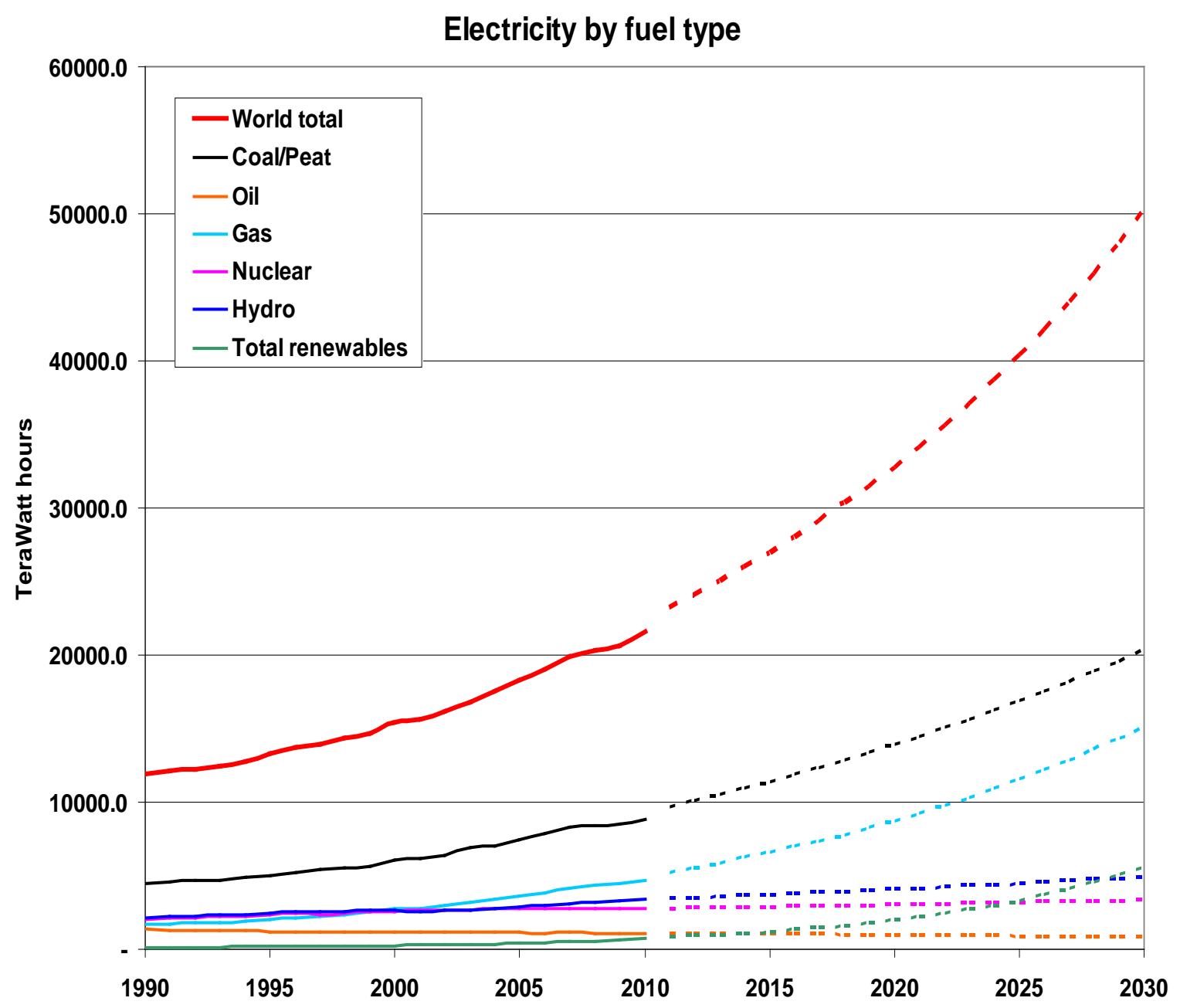

Electrical energy production is set to almost triple over the next two decades.

Energy used to produce electricity has the greatest potential for production from renewable sources.

Telecommunications networks and ICT equipment use electrical energy.

As renewable energy production grows and the environmental impact reduces the negative impact of ICT also reduces. 


\section{$\mathrm{CO}_{2}$ from electricity generation}

$\mathrm{CO}_{2}$ From Electricity Generation

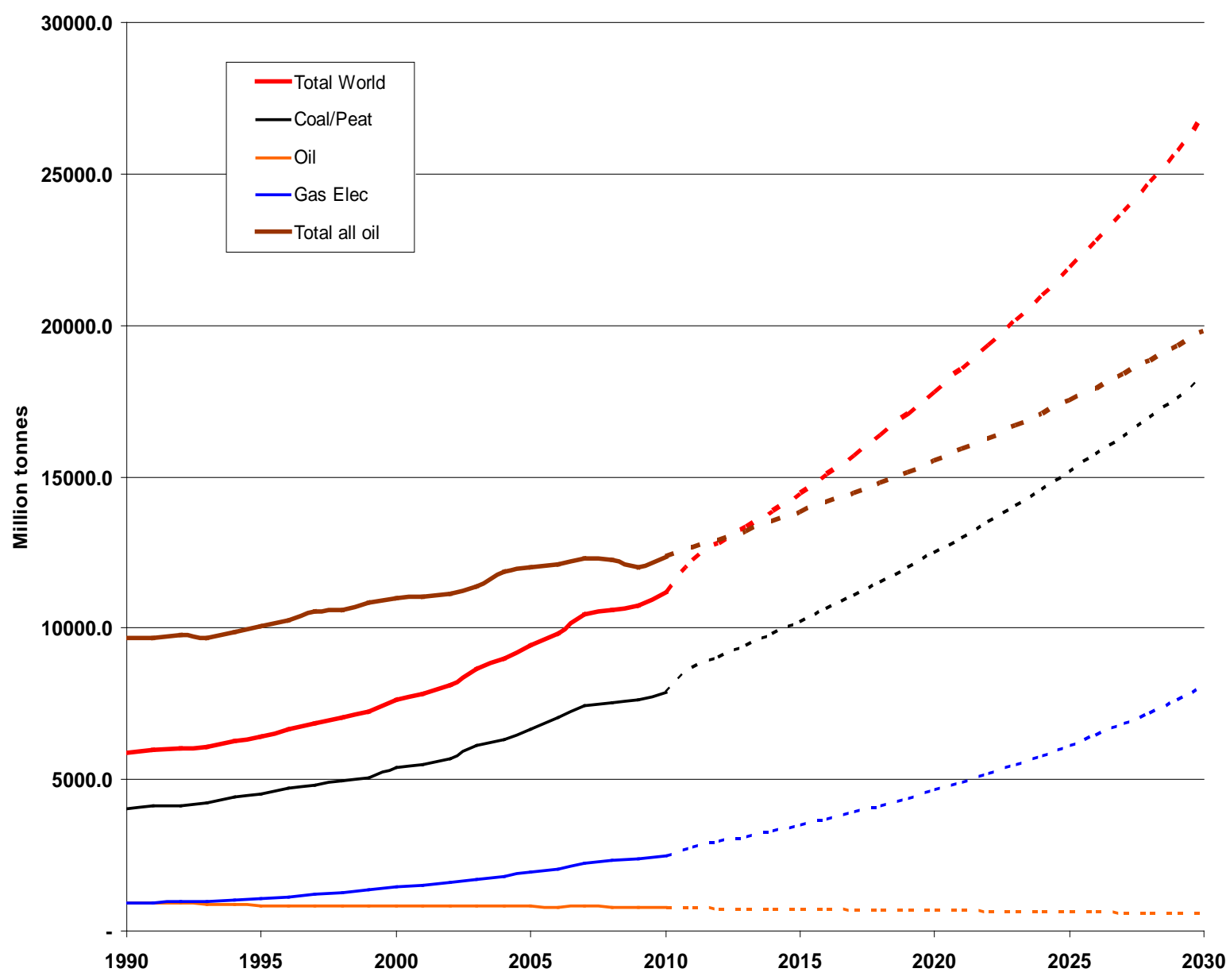

Coal dominates $\mathrm{CO}_{2}$ emissions from electricity production.

Electricity from oil has the smallest contribution and is declining.

Gas is relatively clean compared to coal so $\mathrm{CO}_{2}$ growth is slower than coal.

Also shown is the curve for $\mathrm{CO}_{2}$ from all oil usage. Electricity emissions are set to pass total oil emissions around 2012.

Note: electricity emissions are reduce by greater use of renewables, Majority of oil emissions are not! 


\section{Transport - Oil Use}

Transport Energy use

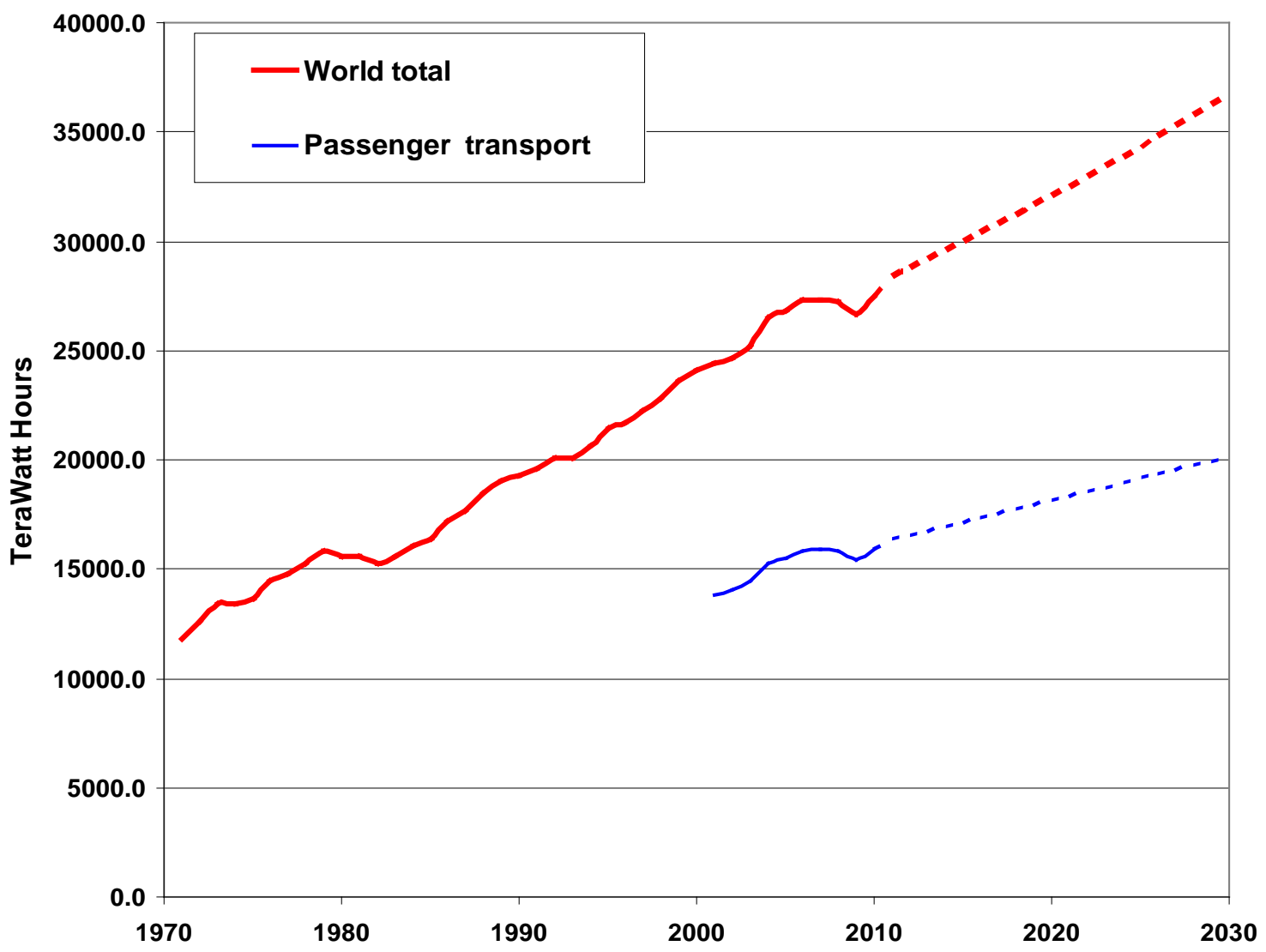

Transport accounts for $\sim 60 \%$ of all oil use.

$\sim 60 \%$ of oil used for transport is used for passenger travel.

This is a sector that ICT and broadband telecomms could offset via high quality low latency video conferencing, remote whiteboard,video calls etc. and e-commerce and e-government generally. 


\section{Transport $-\mathrm{CO}_{2}$ emissions}

Transport $\mathrm{CO}_{2}$ Emissions

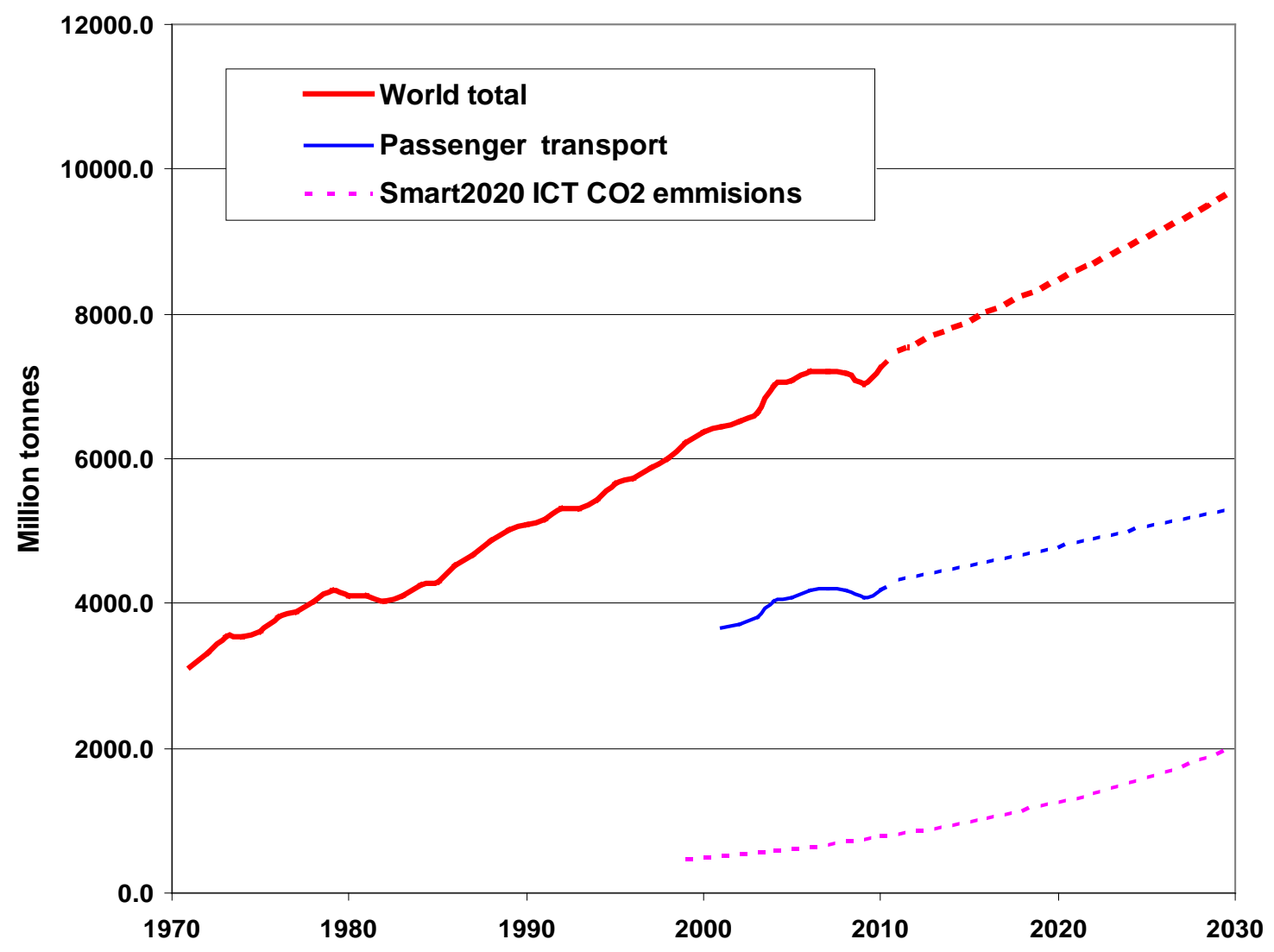

Transport produces $\sim 22 \%$ of the worlds $\mathrm{CO}_{2}$ Emissions and is not mitigated by renewable energy electricity production.

Also shown is the Smart2020 estimates for ICT $\mathrm{CO}_{2}$ contribution modified to take into account and $11 \%$ growth of renewables for electricity generation. This is $-2.3 \%$ of world emissions in 2010.

Because ICT emission are mainly produced from electricity generation it directly benefits from any increase in renewable electricity generation. 


\section{Smart2020 estimates of ICT $\mathrm{CO}_{2}$ contributions}

The global footprint by subsector

Emissions by geography

$\%$ of $\mathrm{GtCO}_{2} \mathrm{e}$

Telecoms infrastructure

and devices

Data centres

PCs, peripherals and printers*

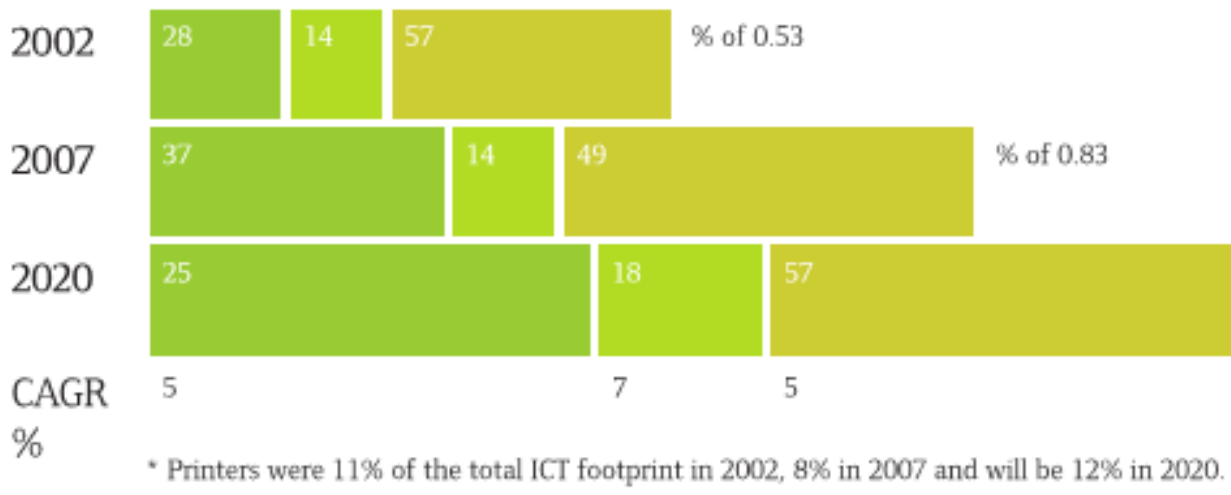

- Telecommunications networks estimated to contribute $25 \%$ of ICT $\mathrm{CO}_{2}$ in 2020.

- Where does this come from and can it be reduced? 


\section{Smart 2020 - ICT offsetting CO2 emissions}

Fig. 8 ICT: The enabling effect

$\mathrm{GtCO}_{2} \mathrm{e}$

7.8 $\mathrm{GtCO}_{2} \mathrm{e}$ of ICT-enabled abatements are possible out of the total BAU emissions in 2020

$\left(51.9 \mathrm{GtCO}_{2} \mathrm{e}\right)$

The SMART opportunities including dematerialisation were analysed in depth

Industry

Smart motors

Industrial process automation

Dematerialisation ${ }^{\star}$ (reduce production of DVDs, paper)

Transport

Smart logistics

Private transport optimisation

Dematerialisation (e-commerce, videoconferencing, teleworking)

Efficient vehicles (plug-ins and smart cars)

Traffic flow monitoring, planning and simulation

Buildings

Smart logisticst

Smart buildings

Dematerialisation (teleworking)

Smart grid $\neq$

Smart grid

Efficient generation of power,

combined heat and power (CHP)

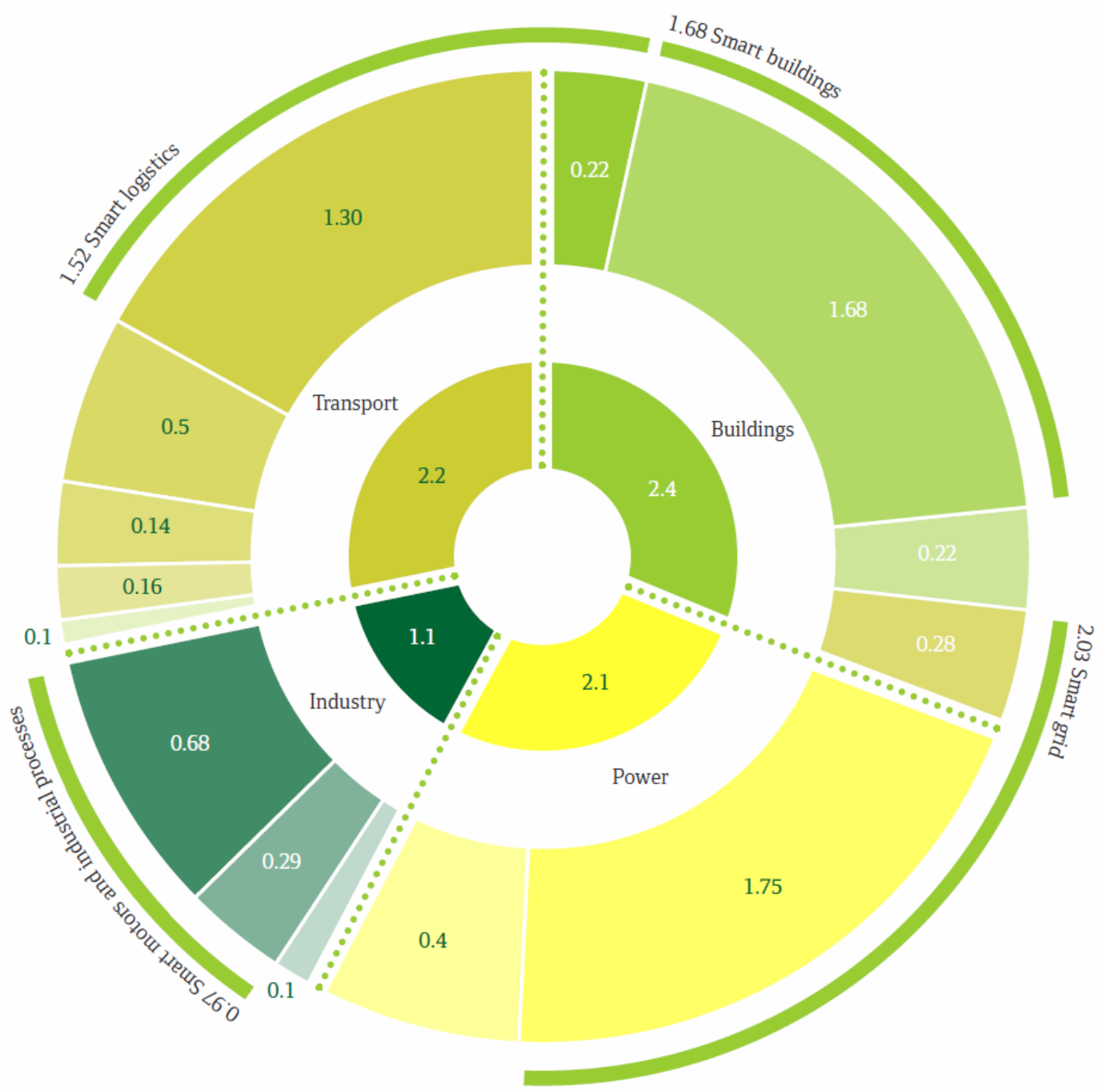




\section{Telecommunications energy Use}

- Telecommunications energy consumption is driven by:

- Growth in usage

- both time on line and higher sustained bandwidth rates.

- particularly in the developed world - predominantly OECD

- Growth in customers/subscribers

- mainly fixed line broadband and Mobile

- adoption/deployment of high bandwidth access e.g. FTTH

- particularly in the developing world - predominantly non OECD 


\section{User bandwidth growth \\ Drives network costs and energy consumption}

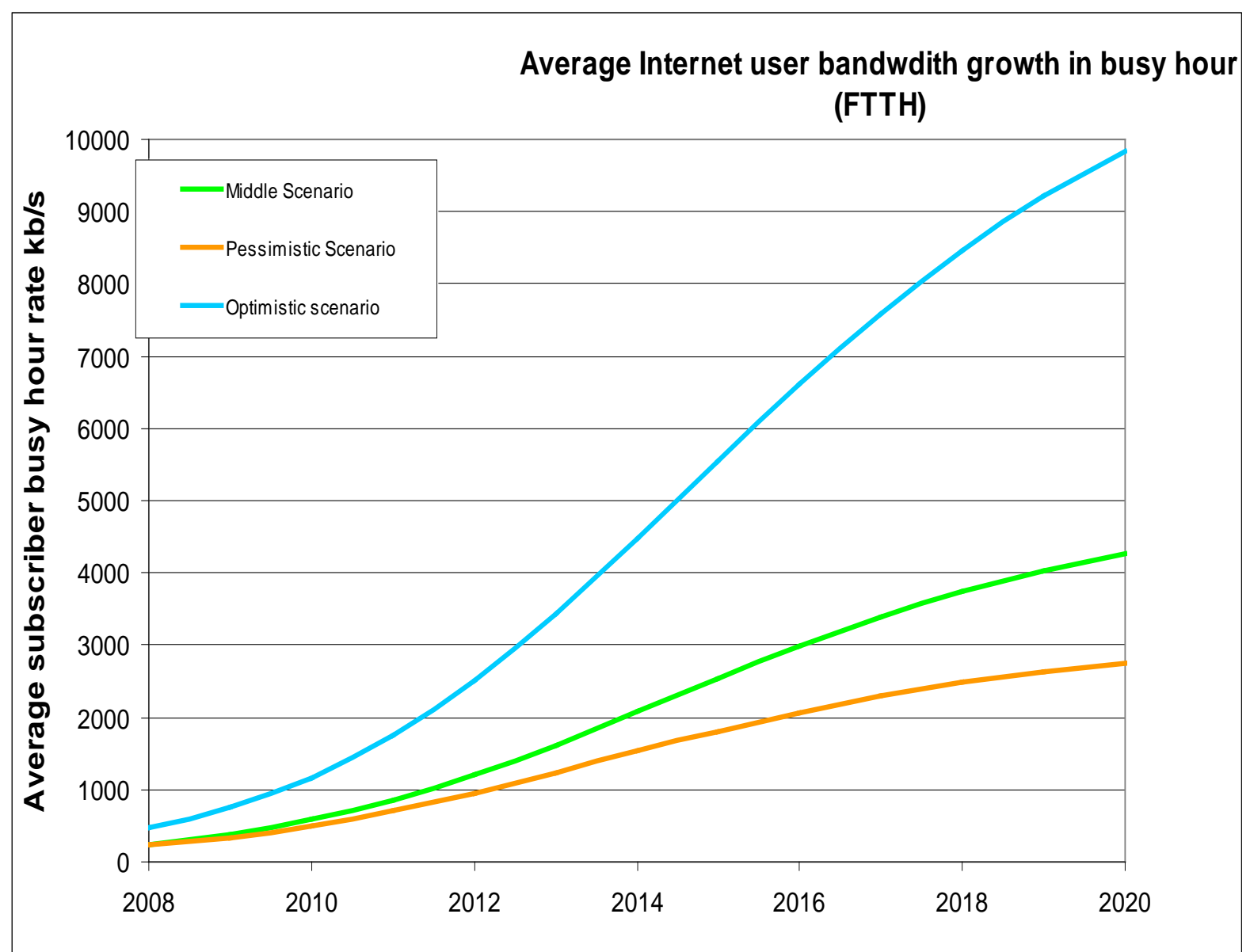

User bandwidth growth scenarios: the major growth is driven by personalised video rather than broadcast video and a growing transition from standard definition to HD quality (assumes 1080p bandwidth would grow to $\sim 30 \mathrm{Mb} / \mathrm{s}$ to remove compression artefacts).

The different scenarios show different growth in personalised video usage and adoption and delivery of HD media. 


\section{Growth in Users and technology}

Growth of major telecomms services

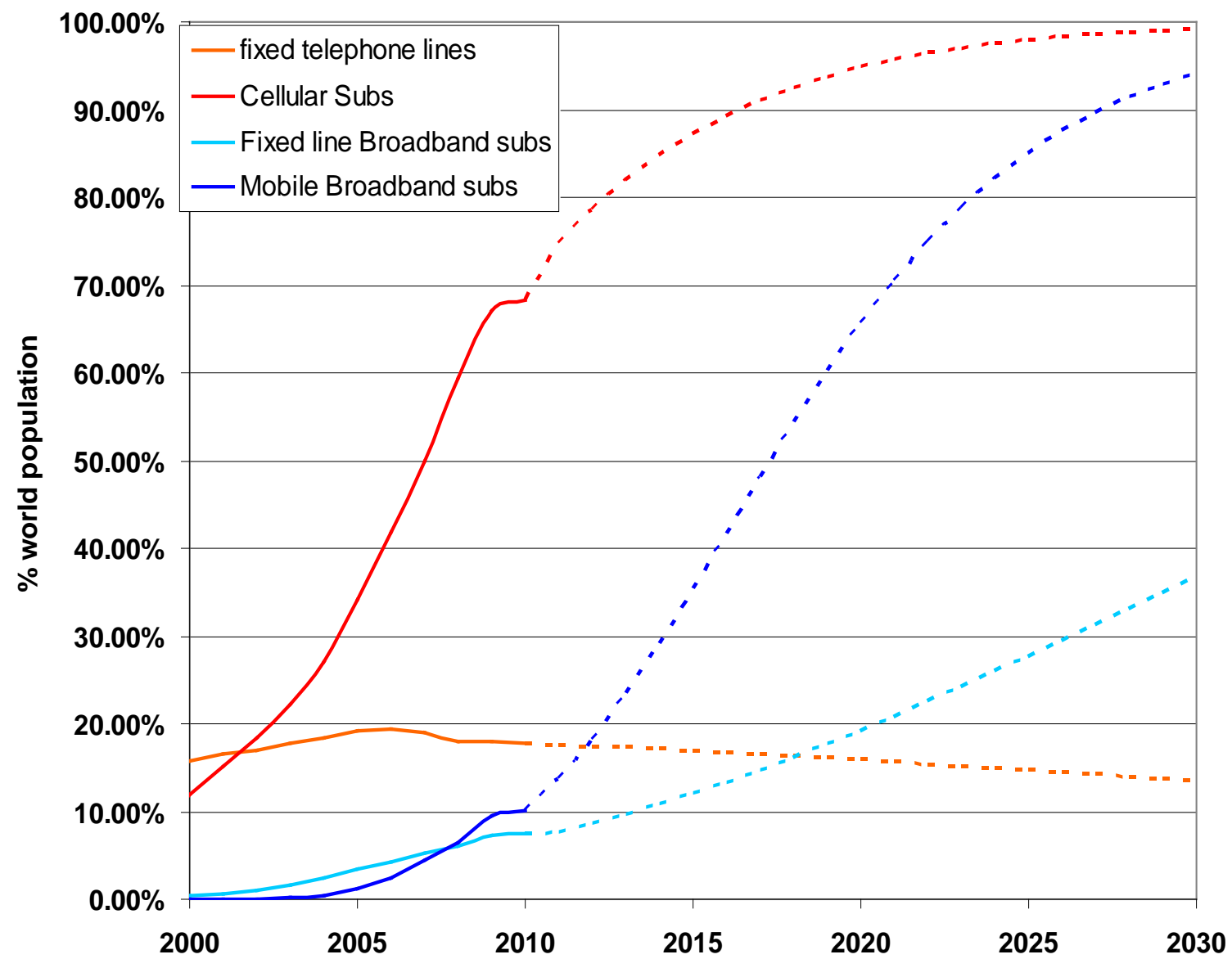

Growth of mobile both cellular and broadband services, particularly in the developing world, dominates the growth of communications services. note: Broadband substitutes NB cellular i.e. is a subset of cellular users.

Fixed line broadband growth is slower due to the need to build infrastructure in the developing world.

Note: Kinks around 2008-9 are due to world recession and assumption that recovery occurs from 2011.

Source for data to 2009 - ITU 


\section{Technology substitution trends}

World Technology Volumes

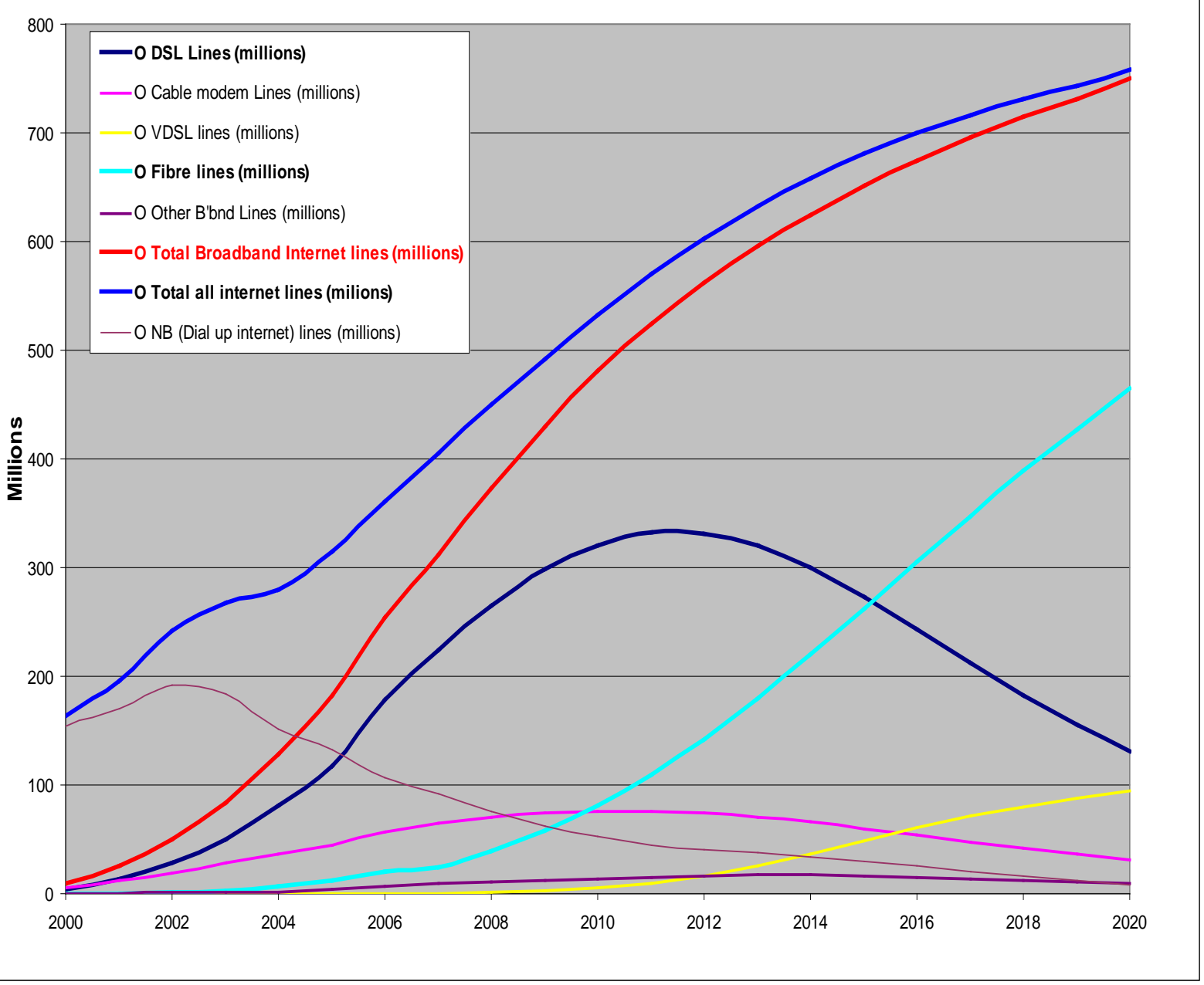

A substitution model such as this is required for self consistent forecasts of the energy consumed by telecommunications networks.

Network bandwidth depends on relative deployments of access technologies. In the developed world new generations of technology substitute older technologies.

In the developing world it can be expected that countries installing new infrastructure will adopt latest generation technology and leap-frog developed countries. 


\section{Telecoms energy consumption}

Energy consumption of ICT \& Telecommunications

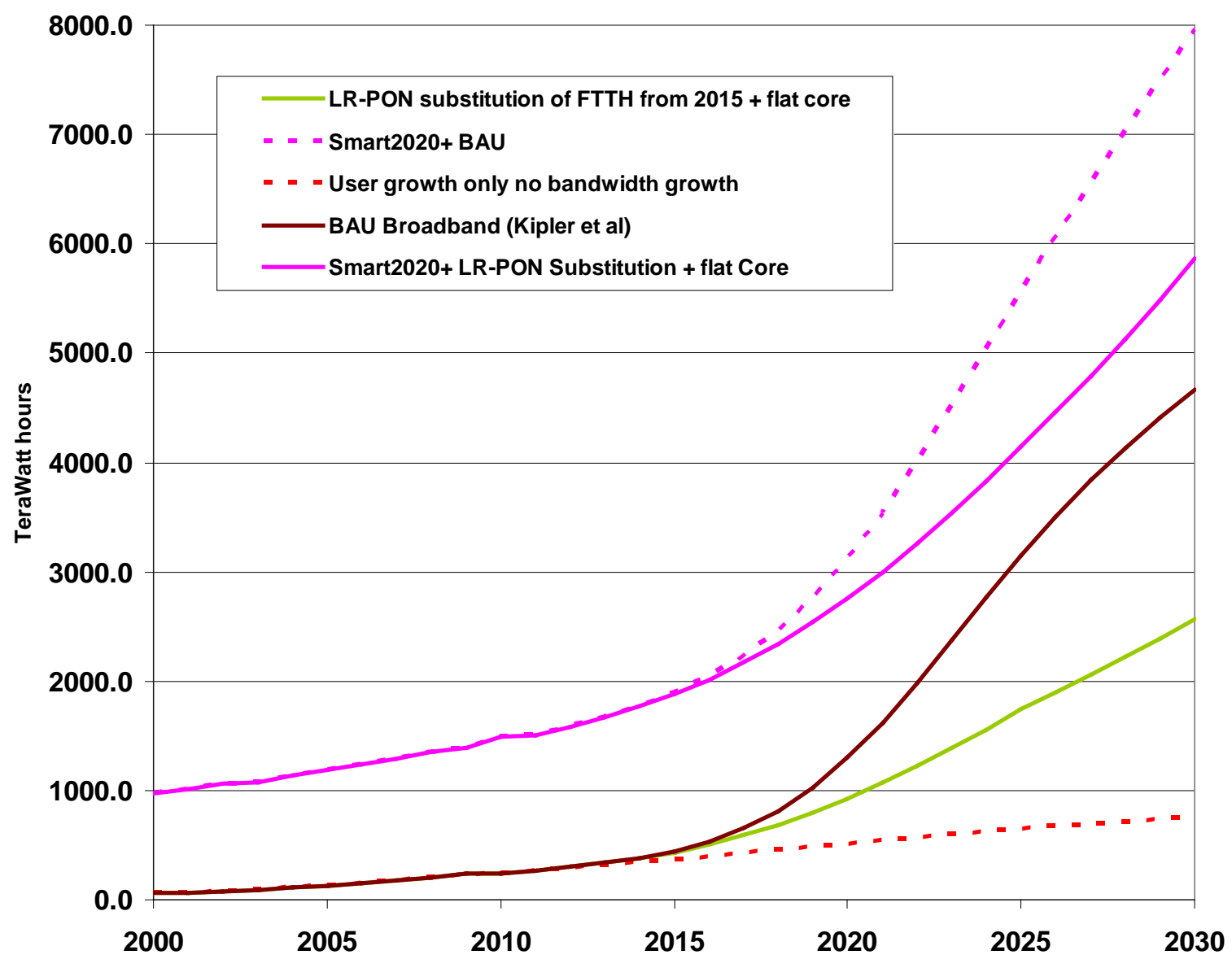

Combining growth in user bandwidth with user and technology growth, taking into account technology substitution, energy consumption for telecommunications can be derived.

The effect of user and technology growth only is shown by the red dashed line.

The brown line shows the effect of increasing user bandwidth for the BAU network (after Kilper et al).

The green curve shows the effect of introducing LR-PON + flat core (assumed to be introduced after 2015).

The magenta curve shows an estimate of ICT energy consumption based on the Smart 2020 report but modified by the effects of bandwidth growth. 


\section{Telecoms technology energy consumption - BAU}

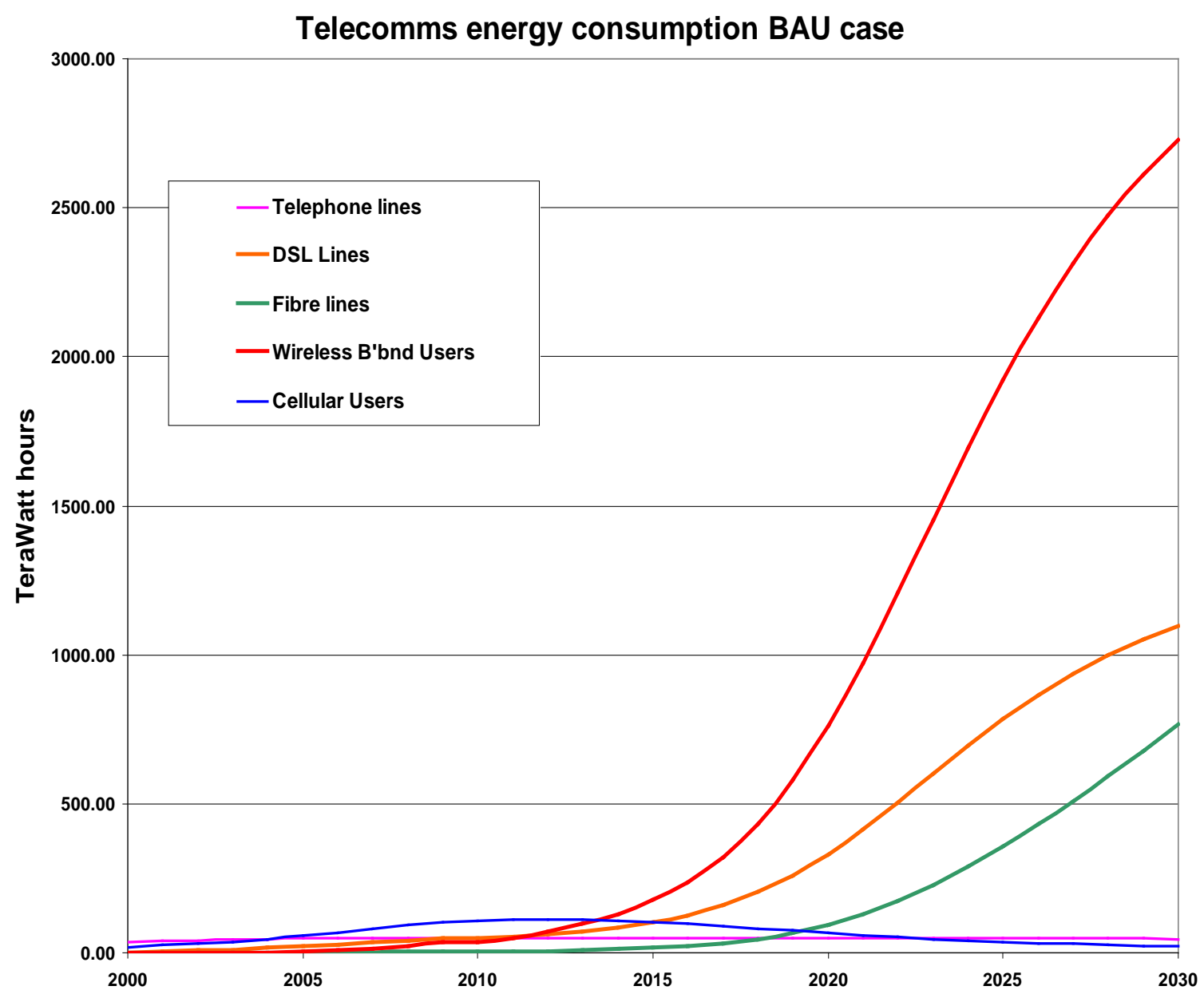

Mobile broadband dominates the power consumption simply because of the huge numbers and projected growth.

Narrow band services, fixed line telephony and voice cellular are small in comparison. 


\section{Telecoms technology energy consumption LR-PON + flat core}

Telecomms energy LR-PON + flat core

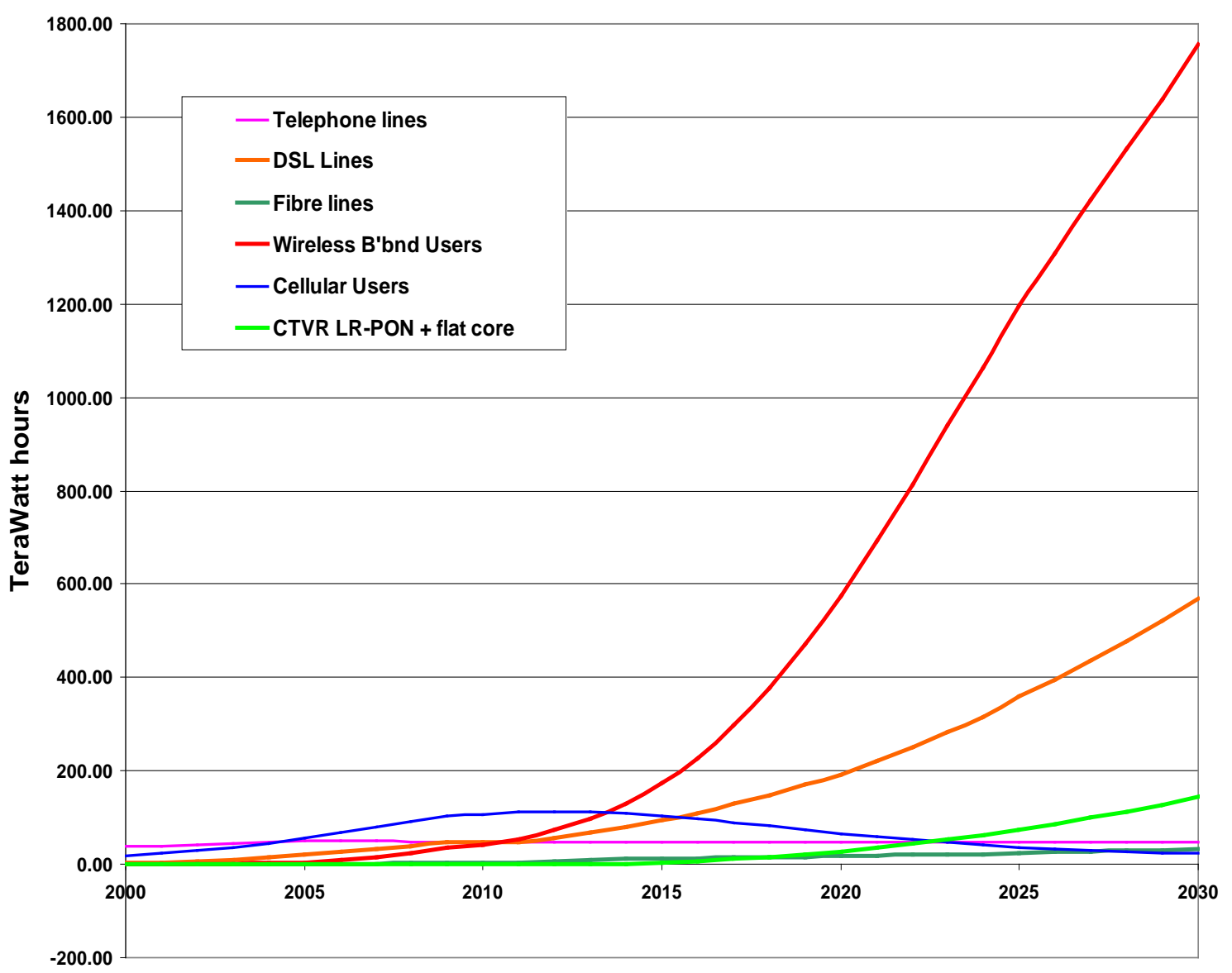

Mobile broadband still dominates the power consumption but the total power consumed is reduced by $\sim 1000$ TWhrs by 2030 due to off loading traffic onto the LR-PON $f$ flat core network.

The original fixed line broadband, fibre and DSL technologies have similarly reduced. and are substituted by LR-PON.

Total power consumption is reduced by $57 \%$ compared to BAU case 


\section{Telecoms $\mathrm{CO}_{2}$ emissions}

CO2 emmissions for Telcomms networks

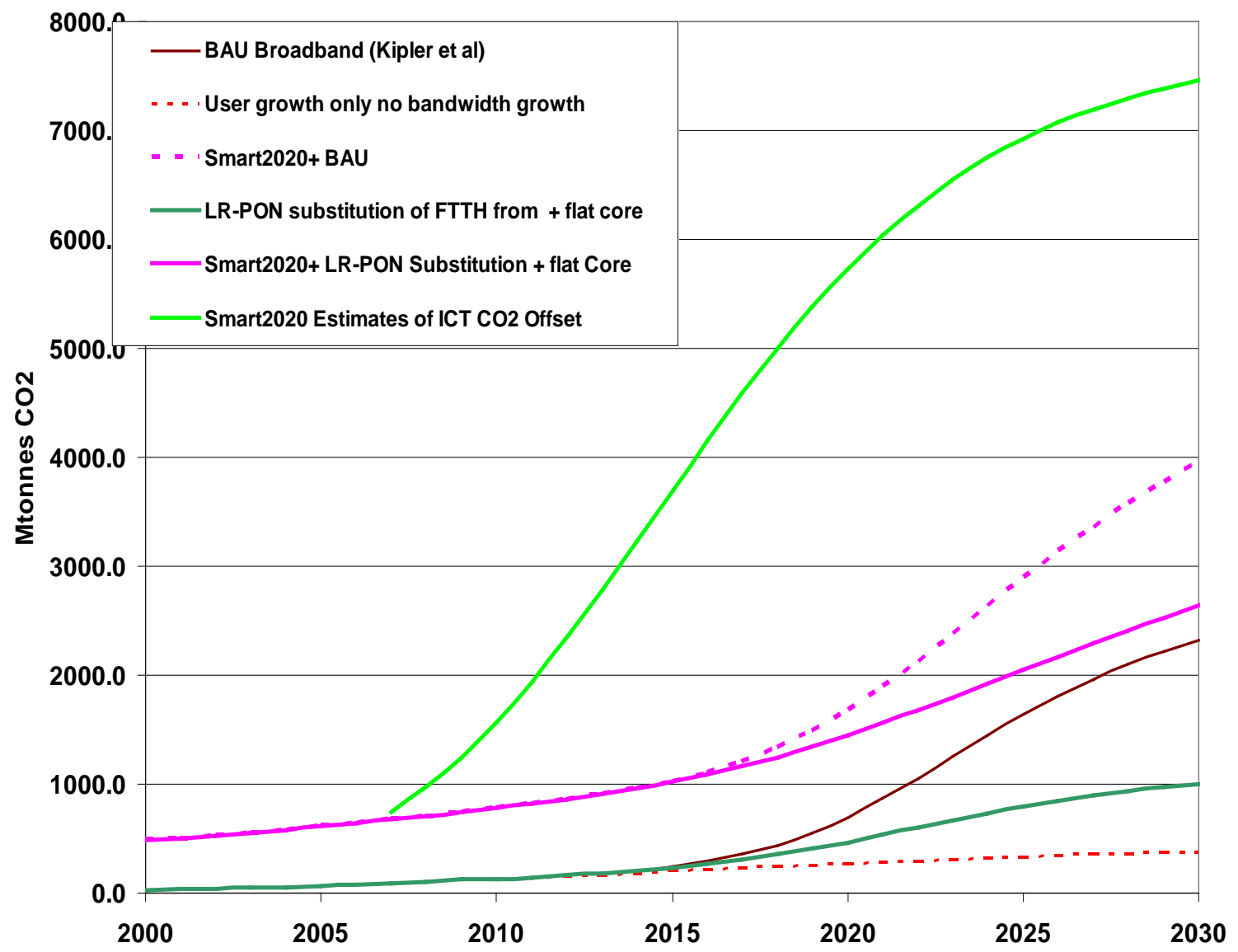

These curves show the resulting CO2 emissions from telecoms networks and the total ICT emissions derived from the Smart2020 report.

The LR-PON +flat core, assumed to be introduced from 2015 , reduces emissions by $40 \%$ compared to the BAU case.

The bright green curve shows the offset of $\mathrm{CO} 2$ emissions identified in the smart 2020 report.

The percentages of telecoms to ICT emissions for 20202030

BAU case $42 \%$

LR-PON + flat core $32 \%$ Smart2020estimate $25 \%$ The increase over Smart2020 due to increased energy consumption with increasing user bandwidth (Kilper et al)

\section{ICT always produces a net benefit to offsetting GHG emissions}




\section{Telecoms $\mathrm{CO}_{2}$ reduction strategies}

- Wind and solar energy for remote network nodes:

- Wireless base stations

- Amplifier node for LR-PON

- Small local exchanges/COs

- If not eliminated by LR-PON solutions.

- Bandwidth mitigation

- Turn traffic as early as possible to avoid growing core traffic.

- CPE storage to reduce data centre storage.

- Or thin client technology to reduce CPE power consumption.

- Note: telecoms and ICT directly benefit from renewable energy for electricity generation. 


\section{Access Technology Evolution - by WDM overlay}

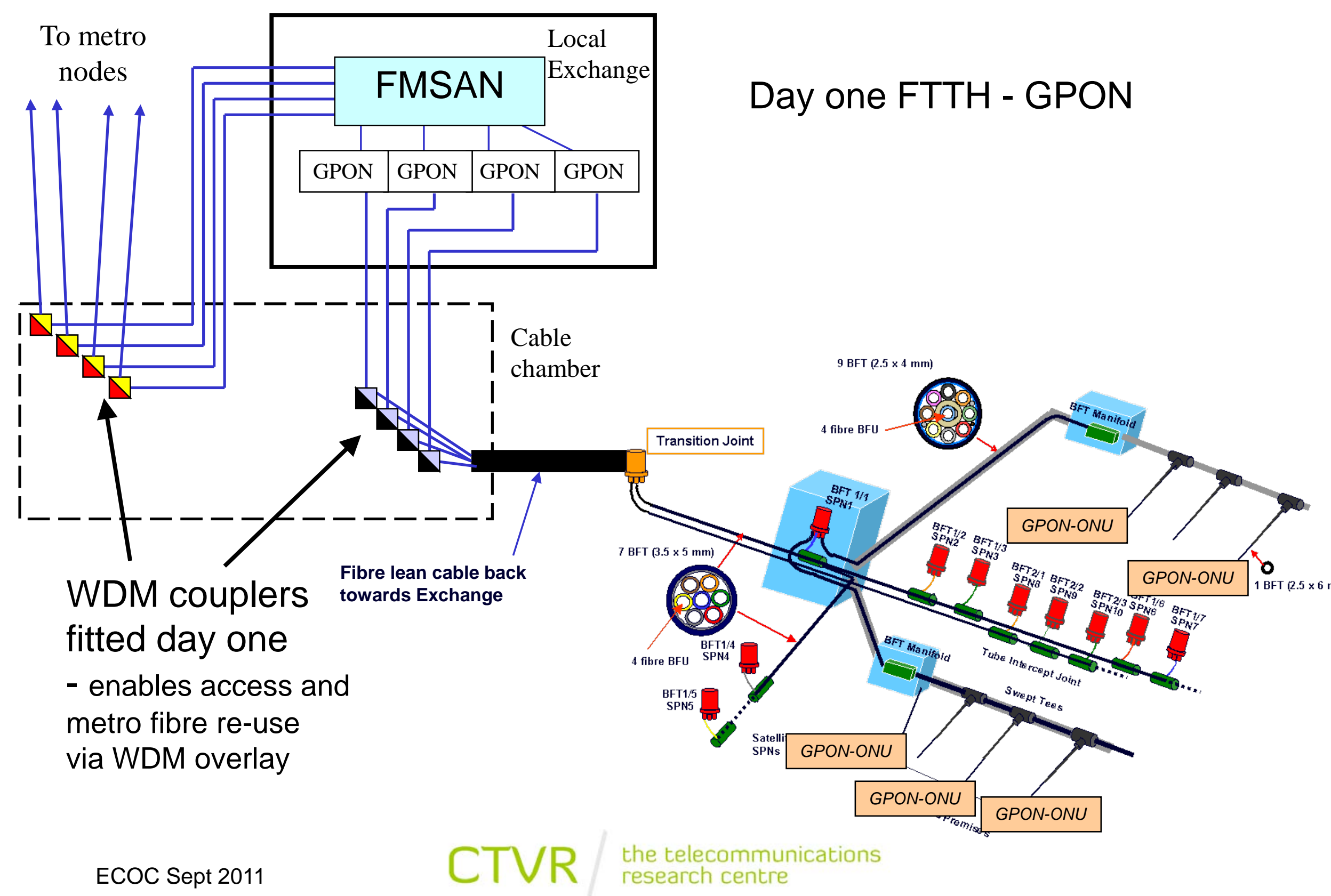




\section{Access Technology Evolution - by WDM overlay}

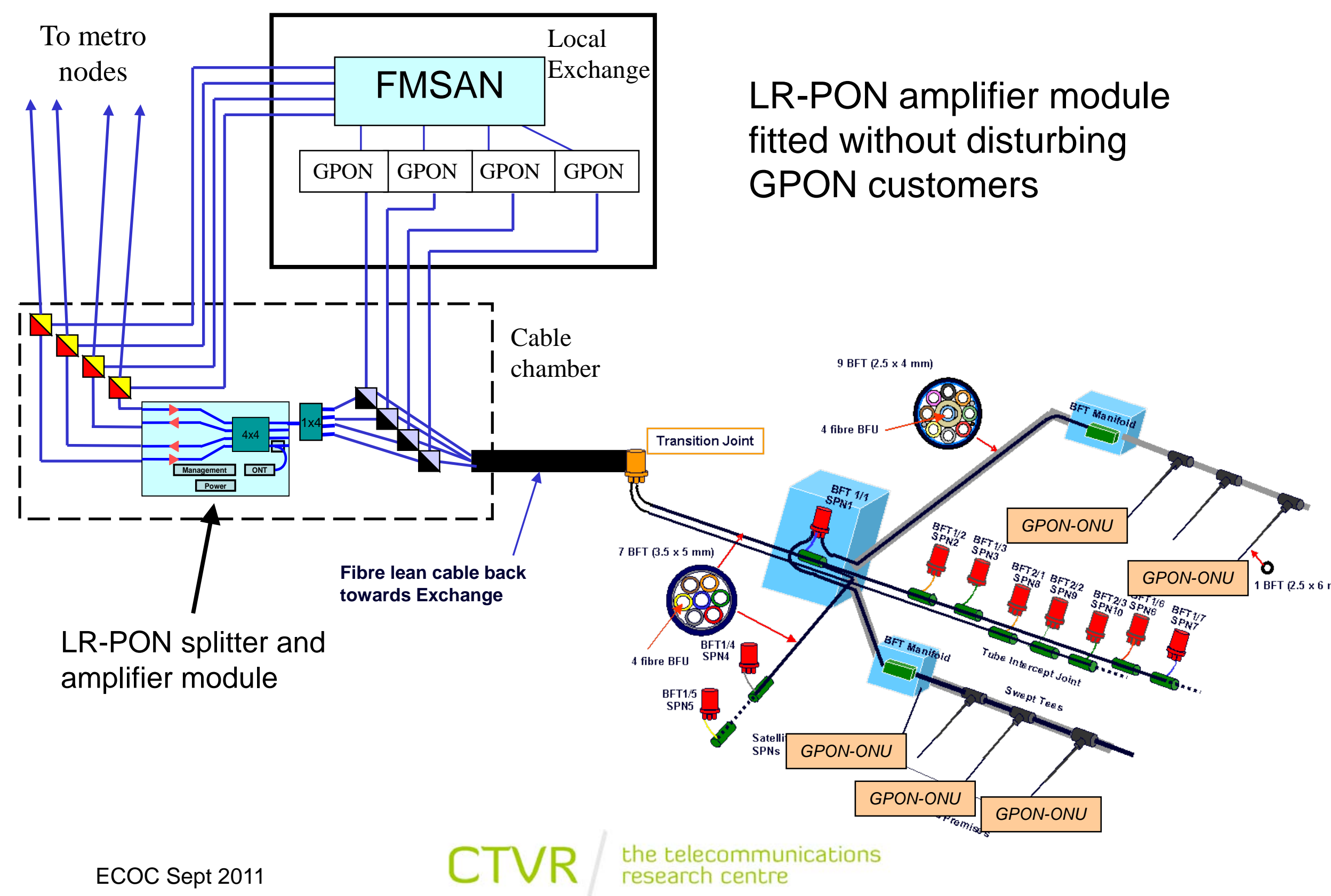




\section{Access Technology Evolution - by WDM overlay}

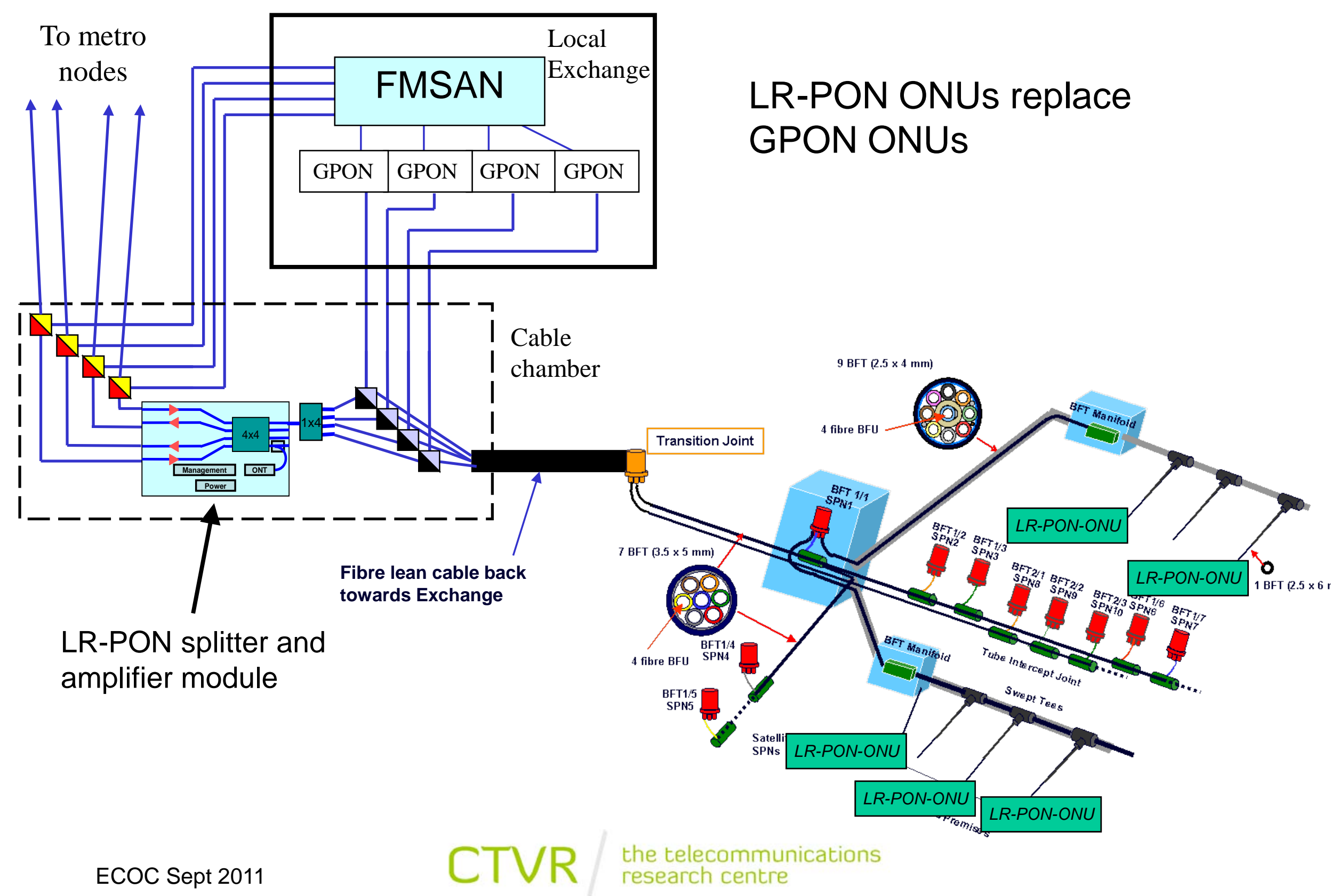




\section{Access Technology Evolution - by WDM overlay}

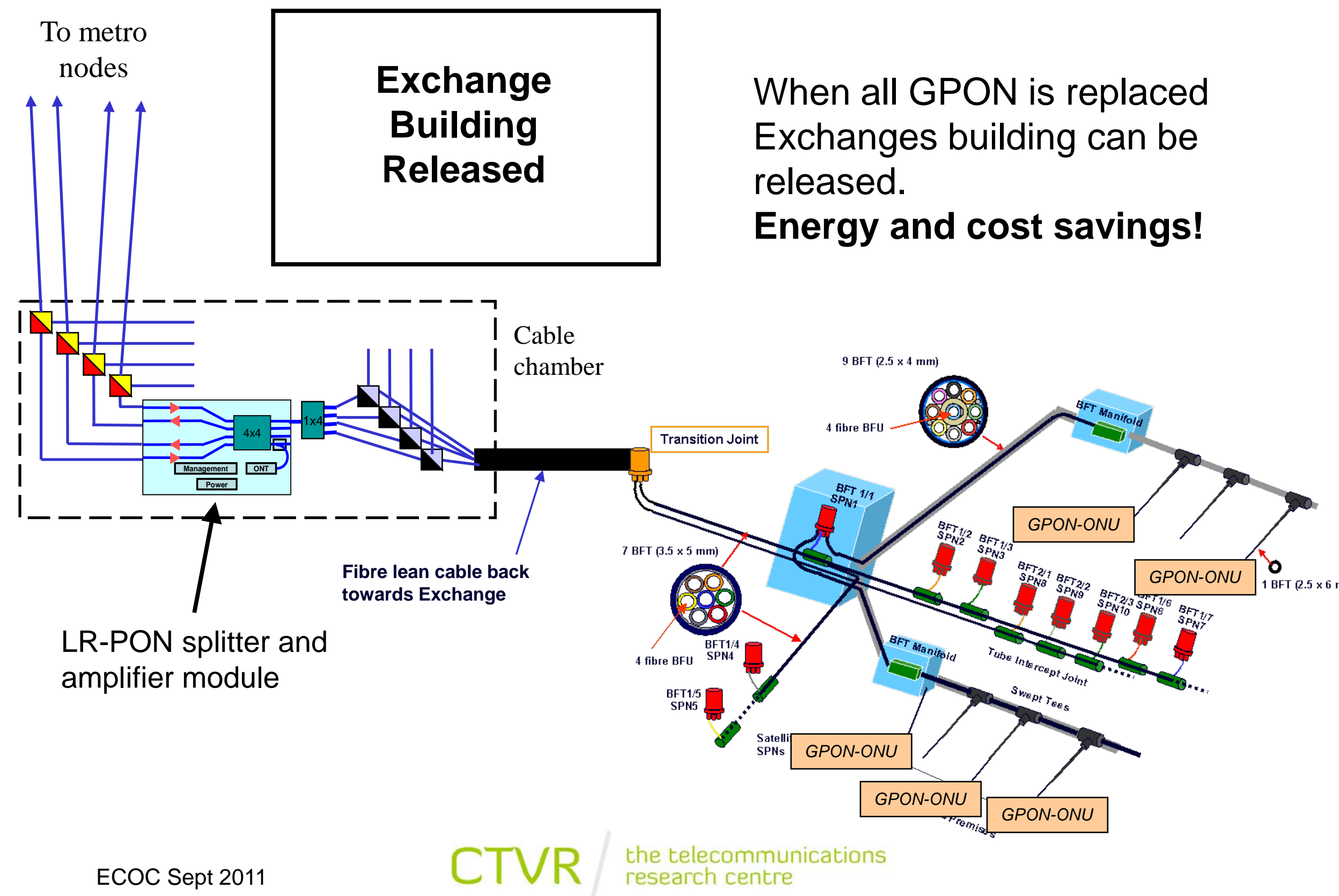




\section{Evolution of LR-PON - by WDM upgrade}

Working Metro-node

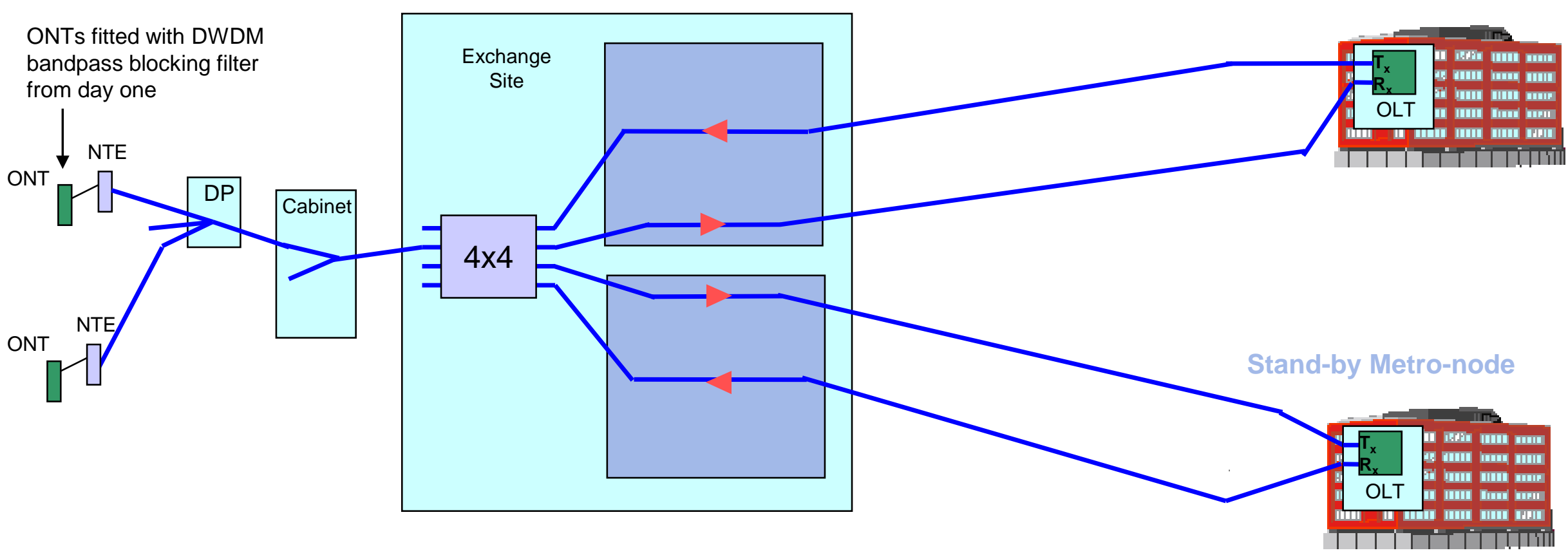

Initial LR-PON assumed to use a single wavelength and two fibre working in the long reach section from exchange site to metro-node 


\section{Evolution of LR-PON - by WDM upgrade}

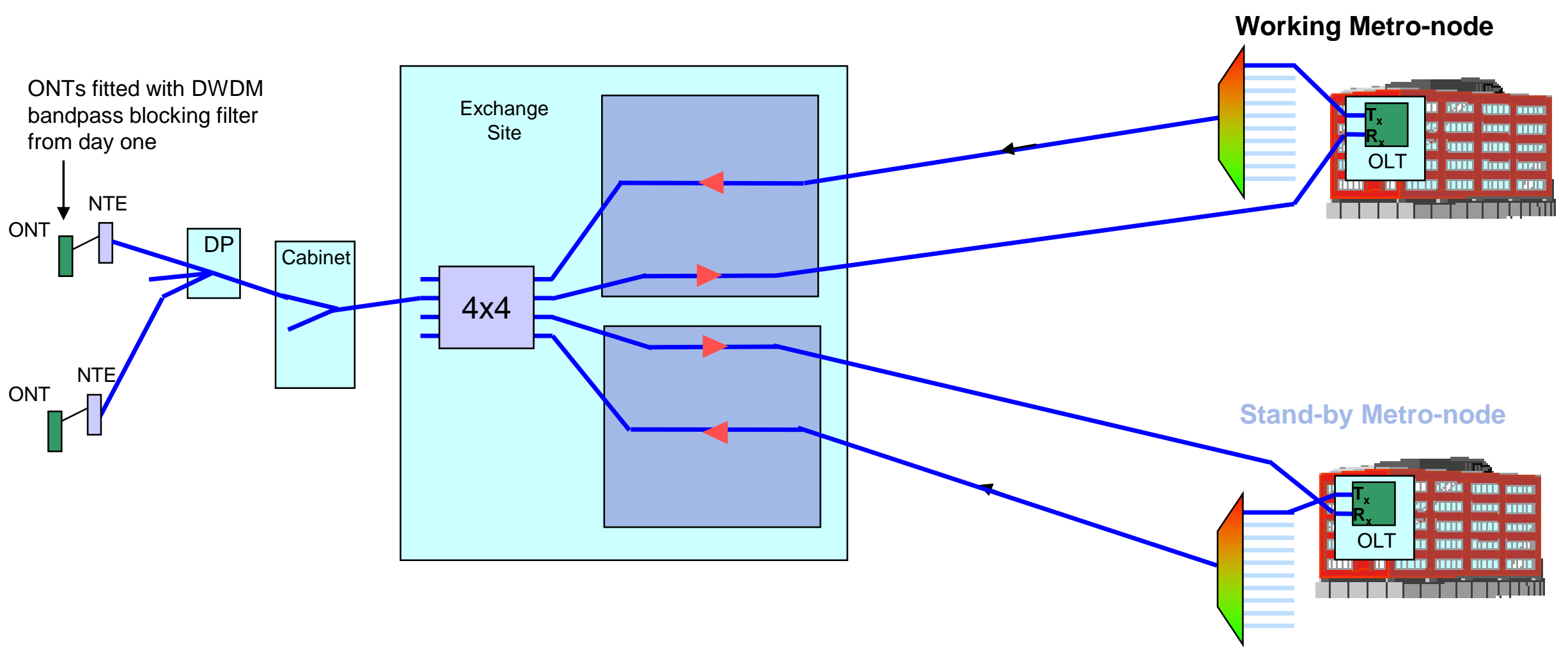

DWDM can be added as bandwidth demands increase.

Note: not needed until user sustained rates exceed 20Mb/s for 512 split LR-PON 


\section{Evolution of LR-PON - by WDM upgrade}

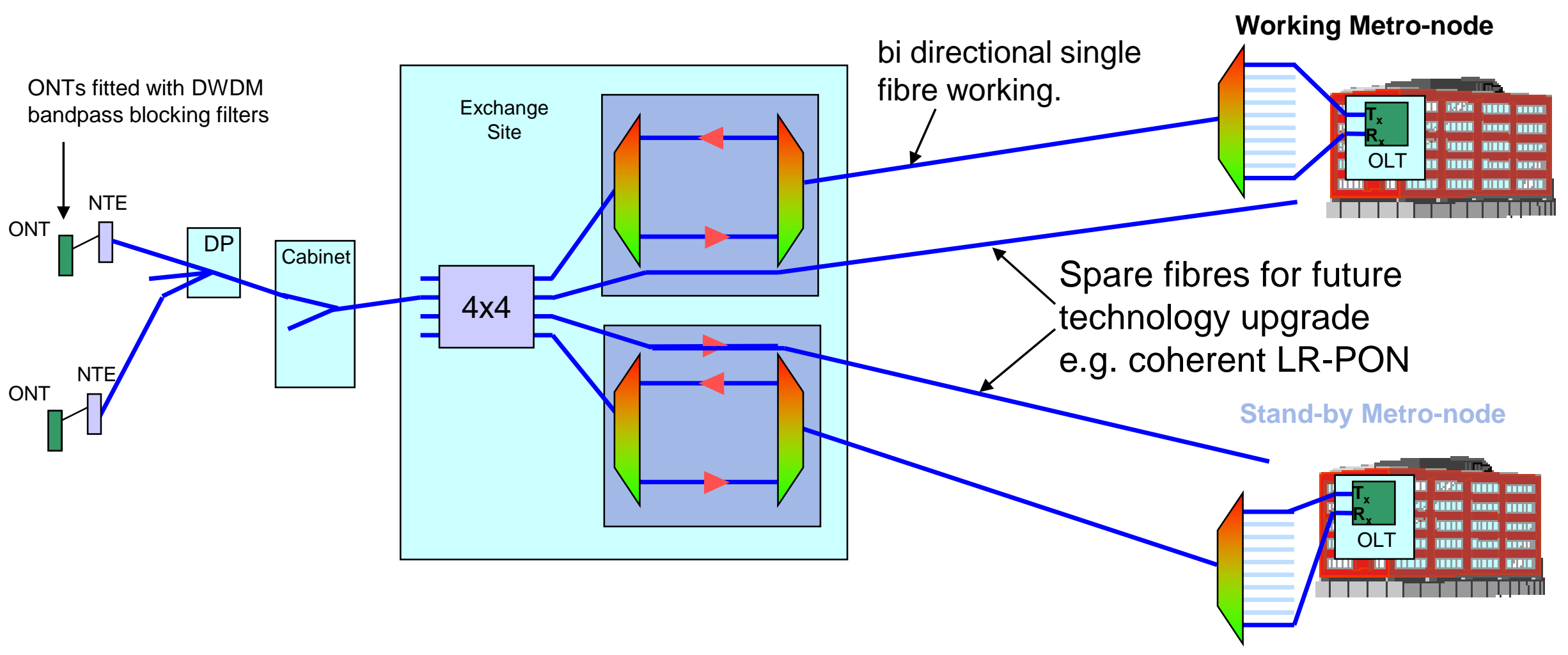

With WDM added bi-directional, single fibre working can be used in the long reach part of the LR-PON leaving two fibres spare for future technology upgrades. 


\section{Evolution of LR-PON - by WDM upgrade}

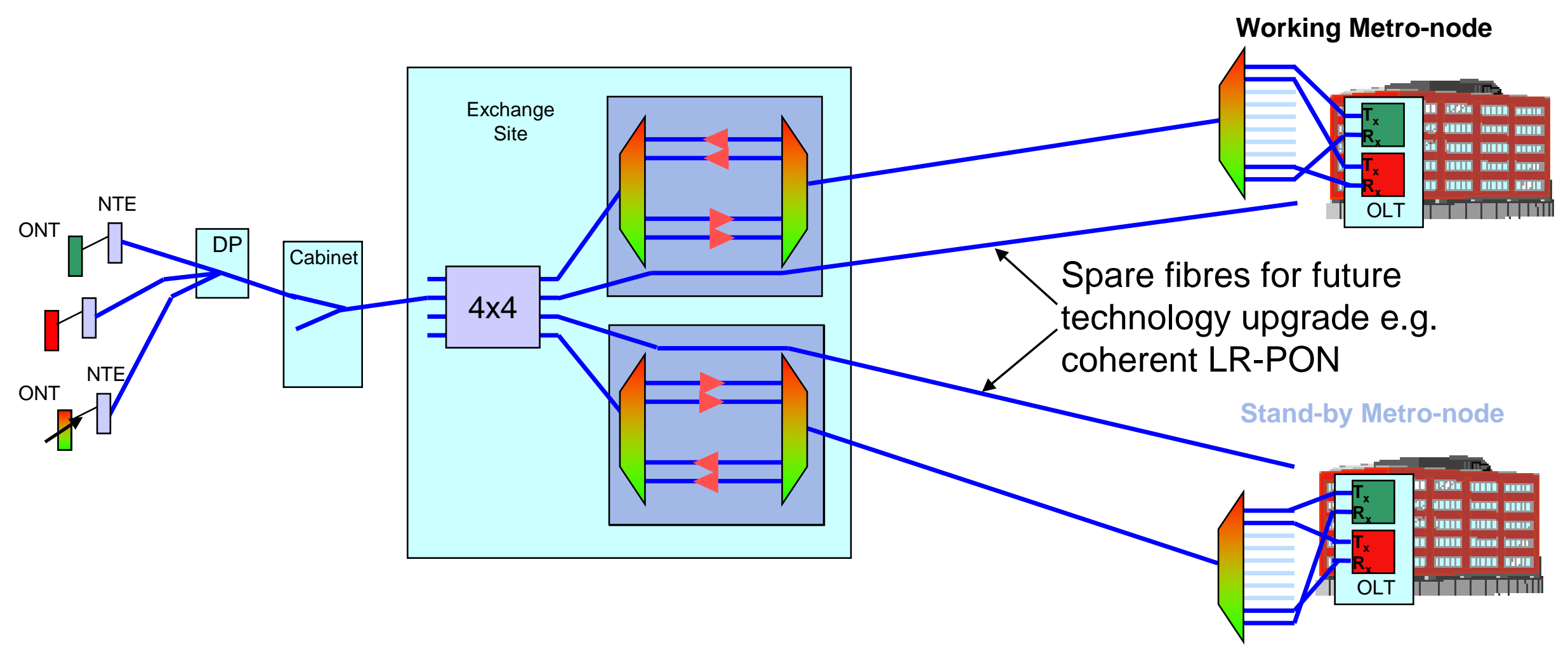

Bandwidth upgrade is simple addition of OLT cards at the metro-node and ONU euiped to receive the new waveleths.

When tuneable receivers are installed at the ONU full wavelength flexibility is enabled. 


\section{Summary}

- ICT and telecommunications are a solution towards combating climate change.

- We maintain that LR-PON + flat optical core offers:

- An economic and environmentally sustainable solution.

- An evolvable solution adaptable to new technologies

- Ability to grow user peak rates and user sustained bandwidth by several orders of magnitude.

- Mobile Broadband will dominate telecoms energy consumption for the next two decades.

Reduce impact via:

- A common network for wireless backhaul and fixed network services?

- Off-load of mobile broadband traffic onto fixed network via WiFi equipped ONUs? 


\section{Thank you}

